
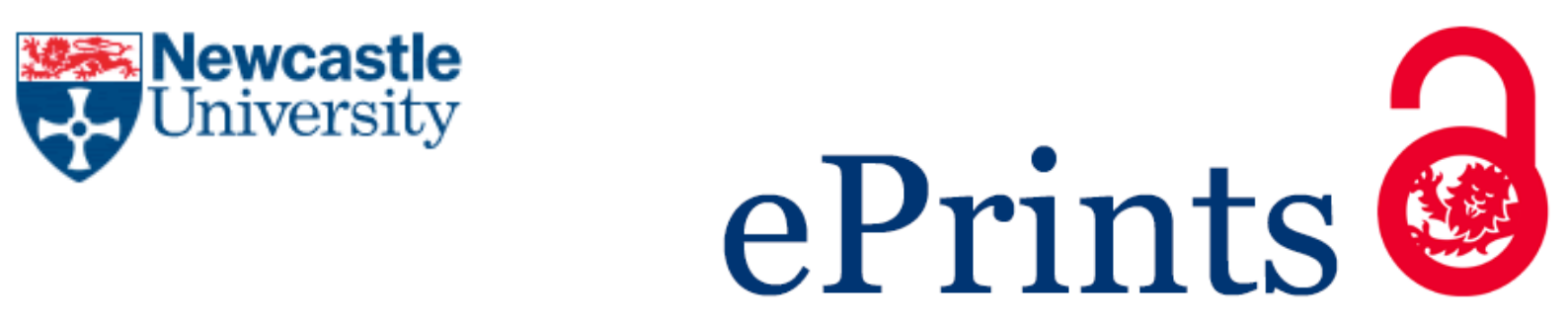

Morris R, Lord S, Bunce J, Burn D, Rochester L. Gait and cognition: mapping the global and discrete relationships in ageing and neurodegenerative disease. Neuroscience \& Biobehavioral Reviews 2016, http://dx.doi.org/10.1016/j.neubiorev.2016.02.012

\title{
Copyright:
}

(C) 2016. This manuscript version is made available under the CC-BY-NC-ND 4.0 license

DOI link to article:

http://dx.doi.org/10.1016/i.neubiorev.2016.02.012

Date deposited:

$03 / 03 / 2016$

Embargo release date:

23 February 2017

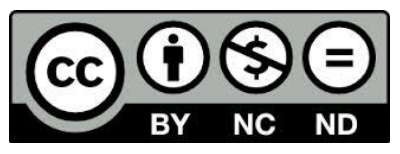

This work is licensed under a

Creative Commons Attribution-NonCommercial-NoDerivatives 4.0 International licence 


\section{Gait and cognition: mapping the global and discrete relationships in ageing and neurodegenerative disease.}

$\underline{\text { Rosie Morris, Sue Lord, Jennifer Bunce, David Burn and Lynn Rochester* }}$

Institute of Neuroscience/Newcastle University Institute of Ageing, Clinical Ageing Research Unit, Campus for Ageing and Vitality Newcastle University, Newcastle upon Tyne, United Kingdom

${ }^{*}$ Correspondence to:

Lynn Rochester PhD

Professor of Human Movement Science

Institute of Neuroscience,

Newcastle University Institute for Aging,

Newcastle University

Newcastle upon Tyne

NE4 5PL

Email: Iynn.rochester@ncl.ac.uk

Tel: (+44) 01912081291

Email: lynn.rochester@newcastle.ac.uk

Word Count: Abstract (170): 170

Article (Excluding abstract): 7270 (incl. text references)

Figures: 5

Tables: 9 


\section{Key Points}

- A robust relationship between gait and cognition is identified in cross sectional studies in older adults, cognitive impairment and PD

- Evidence of selective relationships between discrete gait and cognitive functions in ageing and pathology are subtle but emerging

- A longitudinal gait-cognition relationship is evident in older adults identifying gait may be more sensitive to pathological degeneration compared to cognitive outcomes

- Comprehensive measurement of gait and cognition will consolidate knowledge of specific relationships

- Gait may be a surrogate marker of cognitive impairment and cognitive decline

\section{ABSTRACT}

Recent research highlights the association of gait and cognition in older adults but a stronger understanding is needed to discern coincident pathophysiology, patterns of change, examine underlying mechanisms and aid diagnosis. This structured review mapped associations and predictors of gait and cognition in older adults with and without cognitive impairment, and Parkinson's disease. Fifty papers out of an initial yield of 22,128 were reviewed and a model of gait guided analysis and interpretation. Associations were dominated by the pace domain of gait; the most frequently studied domain. In older adults pace was identified as a predictor for cognitive decline. Where comprehensive measurement of gait was conducted, more specific pathological patterns of association were evident highlighting the importance of this approach. This review confirmed a robust association between gait and cognition and argues for a selective, comprehensive measurement approach. Results suggest gait may be a surrogate marker of cognitive impairment and cognitive decline. Understanding the specific nature of this relationship is essential for refinement of diagnostics and development of novel therapies.

Keywords: gait, cognition, ageing, Parkinson's disease, cognitive impairment 


\section{INTRODUCTION}

Gait provides a marker of global health and is an important tool as a predictor for health status and survival in older adults (Hausdorff et al., 2001; Studenski et al., 2011). Gait is no longer regarded as purely a motor task. An extensive body of research has established that safe and effective gait requires input from higher cognitive areas (Hausdorff et al., 2005). Research over the past decade has refined our understanding of the relationship between gait and cognition to reveal compensatory cognitive strategies which vary as a function of age and pathology (Hausdorff et al., 2005). Cross sectional studies identify associations between gait and cognition in normal ageing and neurodegenerative disease (Yogev et al., 2005; ljmker and Lamoth, 2012; Verlinden et al., 2013a; Lord et al., 2014) as supported by neuroimaging studies (Holtzer et al., 2014). Longitudinally, gait emerges as a strong and significant predictor of future cognitive impairment and dementia in older adults (Marquis et al., 2002; Verghese et al., 2007; Buracchio et al., 2010; Mielke et al., 2013).

Gait speed is universally used to reflect gait because of its utility and robust clinometric properties (Wade, 1992). However, due to its inherent complexity and because it is a multidimensional construct comprised of a number of discrete characteristics, gait cannot be represented by a single outcome. Although gait speed is sensitive to pathology, it is neither discriminative nor reflective of subtle and selective alterations of gait expressed in response to change in neuropathology in ageing and disease (Stolze et al., 2001; Verghese et al., 2007; Lord et al., 2014). Selective identification of gait characteristics is therefore critical for discrimination of pathology, identifying specific features of disease progression and discerning the effect of age for detection of shared neural correlates.

To allow for selectivity and specificity a comprehensive range of gait characteristics must be assessed, although there is high covariance among gait characteristics which needs to be accounted for. In response, several groups have proposed gait models that group gait characteristics into gait domains using data reduction techniques such as principle components 
analysis (Verghese et al., 2007; Hollman et al., 2011; Lord et al., 2013; Verlinden et al., 2013b). Whilst the models are comparable, there are subtle differences. For example Verghese and colleagues collated eight gait characteristics to form three domains; pace, variability and rhythm whereas Lord and colleagues obtained two further domains; asymmetry and postural control by collating 16 characteristics. Other models have produced more novel domains such as tandem and turning (Verlinden et al., 2013b) allowing for inclusion of more complex motor tasks. Independent domains of gait (and the characteristics thereof) can then be hypothesised to reflect independent neuroanatomical and functional substrates. Similarly for cognition, independent assessments are grouped to examine domains (Martin et al., 2013; Verlinden et al., 2013a; Lord et al., 2014) that are thought to represent independent neural substrates underlying cognitive functions.

Current understanding of disease pathology provides insight into potential associations of gait and cognition. For example, people with Alzheimer's disease $(A D)$ present foremost with deficits in amnestic ability predominantly due to amyloid deposition in the entorhinal cortex and hippocampus (Braak and Braak, 1995), with concordant findings of an association between atrophy of the hippocampus and decreased gait speed and step length (Callisaya et al., 2013). Similarly, people with Parkinson's disease (PD) present with executive attention deficits due to compromised fronto-striatal circuitry (Stern et al., 1993; Burton et al., 2004) and attention also is significantly associated with reduced gait speed and step length (Lord et al., 2014). The question remains however if discrete gait domains share a different association dependent upon cognitive function? Furthermore, if the relationship between gait and cognitive variables is selective one may expect a different signature of impairments to emerge underpinned by the selective influence of pathology. A better understanding of this relationship would strengthen an understanding of the mechanisms of gait impairment, the shared neural and pathological correlates of gait and cognitive function and validate the role of gait as a surrogate biomarker of cognitive decline and pathology (Lord et al., 2014; Mollenhauer et al., 2014). The relationship between gait and cognition however is still an emerging are of work, largely 
due to recent advances in the understanding of gait and improvement in the ability to measure its discrete characteristics. To date a comprehensive investigation of the selective association between independent gait and cognition characteristics has not been undertaken.

The purpose of this review was therefore to undertake a detailed comparison of studies exploring discrete relationships of gait and cognitive domains. For this review, studies were limited to measuring gait under single task conditions. Gait under single task conditions reflects the ability of the cognitive system to control locomotion and to compensate for motor and cognitive deficit as a consequence of ageing and pathology. Therefore it is expected that changes in cognitive function would be reflected in changes in gait performance. Although dual task paradigm studies are extensively used to examine associations of gait and cognition, inconsistent findings are reported due to methodological issues such as diverse concurrent tasks, controlling for baseline task demand and different analysis of calculating dual task interference (Rochester et al., 2014). In addition to these inconsistencies, the underlying cognitive nature of dual task methodology remains unclear and does not reflect baseline cognitive influence on gait; therefore making it difficult to tease out direct underlying neural correlates.

In light of this, the aims of this review are to i) explore evidence for the associations between independent features of gait and cognitive function and ii) identify the longitudinal nature of relationships. We hypothesise that independent gait characteristics would be related to discrete cognitive functions in a specific rather than global manner and the pattern of association would be different with respect to pathology and ageing. In order to address this hypothesis we adopted a model of gait previously used in OA (Lord et al., 2013)(Figure 1) and a comprehensive range of cognitive domains previously described (Emre et al., 2007) to improve consistency, reduce redundancy and retain independence between gait and cognitive features respectively to ease interpretation of results. We mapped individual gait domains (or respective characteristics) to individual cognitive functions to develop a matrix from which to identify discrete relationships. Three different cohorts were included: older adults $(O A)$; those with cognitive 
impairment $(\mathrm{Cl})$; and people with $\mathrm{PD}$, in order to explore gait-cognition associations in pathology and normal ageing. Cross-sectional and longitudinal study designs were examined to identify causality. It is hoped this review will not only to provide a clear understanding of current associations but in addition identify gaps in the literature to inform recommendations for future work.

\section{METHODS}

\subsection{SEARCH STRATEGY}

Three databases were used for the search: Medline, Psychinfo and Scopus. For each of the databases used, three separate searches were performed for the three cohorts included in the review; $\mathrm{OA}, \mathrm{Cl}$ and PD. In total, nine separate searches were completed. Each search used the key terms 'Gait', 'Cognition' and either 'Parkinson's disease', 'dementia' or 'older adults'. For each of the key terms, a list of synonyms were correlated and entered into the search (Table 1). Where possible, MESH headings were used for Medline and Psychinfo. The search was limited for papers published since 1990 to February 2014, written in English language and restricted to full journal articles only.

The initial nine searches were combined into three master databases; 'Parkinson's disease', 'Cognitive Impairment' and 'Older Adults'. Duplicates were then deleted and an initial title screen was performed by the reviewer (RM). After the initial title screen, the titles and abstracts were reviewed by independent reviewers (RM and JB). A review of the full text was needed in incidences where it was unclear from the abstract whether the paper was suitable for inclusion.

\subsection{INCLUSION AND EXCLUSION CRITERIA}


Articles were included if they assessed OA and patients with either a degree of cognitive impairment or PD completing a gait assessment under single task conditions and independently completing a minimum of one cognitive assessment. Cognitive assessments included general cognitive tests (e.g. MMSE/MOCA) as well as tests of attention, executive function, memory, language, processing speed and visuospatial skills. Articles must have completed analysis for gait assessment under single task conditions. Articles were excluded if they only completed cognitive tasks under dual task conditions or if analysis was only reported for dual task conditions. Intervention studies were excluded as well as studies focusing on falls, freezing of gait (FOG) and overall physical activity.

\subsection{DATA EXTRACTION}

A title and abstract screen was undertaken by two independent reviewers; $\mathrm{RM}$ and JB. Three separate data extraction forms were created for the three cohorts. Data from the extraction forms was then transferred into a table. Information included; participant groups, participant characteristics, study type, gait variables measured, gait analysis tool, cognitive domains tested, cognitive assessments used and main study findings. The cognitive impairment cohort included the type of cognitive impairment and for the PD cohort whether participants were ON or OFF medication.

\section{RESULTS}

\subsection{SEARCH YIELD}

The search strategy generated a total of 43,828 papers; after exclusion criteria were applied the search strategy generated a total of 25,487 papers. After duplicates were removed, a total number of 22,128 papers were yielded from the search. The total number of papers were compiled into three databases; OA ( $n=11609), \mathrm{Cl}(n=7919$ and PD ( $n=2600)$. After the initial title 
screen, the total number of papers of interest for each group were OA $(n=168), \mathrm{Cl}(n=119)$ and PD $(n=62)$.

After an abstract screen, 66 papers were eligible for data extraction ( $n=34$ OA, $n=22 \mathrm{Cl}, n=10 \mathrm{PD}) .11$ papers were excluded due to inability to access paper $(n=7)$, duplicate findings $(n=1)$ and studies which were not full journal articles $(n=3)$. Data extraction was completed for a total of 55 papers; 30 for the OA cohort, 15 for the $\mathrm{Cl}$ cohort and 10 for the PD cohort. After data extraction, 9 papers were excluded due to completing only dual task conditions $(n=4)$, not associating gait and cognition $(n=1)$, associating fast speed only $(n=1)$, participants being too young ( $n=1$, all $<60$ years), not completing both independent cognitive domains and gait variables $(n=1)$ and focusing on cognitive reserve $(n=1)$. Four papers (Dodge et al., 2012; Lord et al., 2014), (Kaye et al., 2012) and (Xu et al., 2014) have been identified since the search closed and were added to the data extraction process. The total number of papers used was 50 . The search yield is demonstrated in Figure 2. All articles were originally published in the English language. Publication dates ranged from 2002 (Lord and Menz, 2002; Marquis et al., 2002) to 2014 (Lord et al., 2014; Xu et al., 2014).

\subsection{MEASUREMENT OF GAIT AND COGNITION - METHODOLOGICAL COMPARISONS}

Gait measurement techniques included the use of activity monitors (Rochester et al., 2004; Rochester et al., 2005; Rochester et al., 2008; Gillain et al., 2009; Lord et al., 2010; Maquet et al., 2010; ljmker and Lamoth, 2012), gait walkway systems (Holtzer et al., 2006; Hollman et al., 2007; van lersel et al., 2008; Beauchet et al., 2012; Coelho et al., 2012; Holtzer et al., 2012; Muir et al., 2012; Beauchet et al., 2013; Lord et al., 2013; Martin et al., 2013; Verlinden et al., 2013a; Lord et al., 2014), optokinetic systems (Ble et al., 2005; Amboni et al., 2012), foot pressure sensors (Sheridan et al., 2003; Allali et al., 2010b), infra-red cameras (Kaye et al., 2012; Wild et al., 2013), timed up and go test (Donoghue et al., 2012; Smulders et al., 2013; Xu et al., 2014), timed to walk (Fitzpatrick et al., 2007; Auyeung et al., 2008; Duff et al., 2008; Persad et al., 2008; McGough et al., 2011) and 6 minute walk 
distance test (Lord and Menz, 2002). A number of studies used a combination of techniques listed above (Hausdorff et al., 2005; Yogev et al., 2005; Lamoth et al., 2011; Bramell-Risberg et al., 2012). The majority of studies assessed single gait characteristics but five studies utilised gait domains (Verghese et al., 2007; Amboni et al., 2012; Lord et al., 2013; Verlinden et al., 2013a; Lord et al., 2014).

A variety of cognitive assessments were utilised as shown in Tables 6, 7, 8 and 9 however, several of the same assessments were used in different studies and reported as testing different cognitive domains. Therefore for clarity we've noted studies that either assessed single cognitive assessments in association with gait; (Lord and Menz, 2002; Marquis et al., 2002; Sheridan et al., 2003; Rochester et al., 2004; Ble et al., 2005; Hausdorff et al., 2005; Rochester et al., 2005; Yogev et al., 2005; Alfaro-Acha et al., 2007; Atkinson et al., 2007; Fitzpatrick et al., 2007; Hollman et al., 2007; Inzitari et al., 2007; Auyeung et al., 2008; Duff et al., 2008; Persad et al., 2008; Rochester et al., 2008; van lersel et al., 2008; Deshpande et al., 2009; Gillain et al., 2009; Allali et al., 2010a; Atkinson et al., 2010; Buracchio et al., 2010; Lord et al., 2010; Maquet et al., 2010; Auyeung et al., 2011; Lamoth et al., 2011; McGough et al., 2011; Beauchet et al., 2012; Bramell-Risberg et al., 2012; Coelho et al., 2012; Donoghue et al., 2012; ljmker and Lamoth, 2012; Muir et al., 2012; Taniguchi et al., 2012; Beauchet et al., 2013; Lord et al., 2013; Smulders et al., 2013; Wild et al., 2013; Xu et al., 2014) or grouped assessments to form domains (Holtzer et al., 2006; Verghese et al., 2007; Watson et al., 2010; Amboni et al., 2012; Dodge et al., 2012; Holtzer et al., 2012; Kaye et al., 2012; Martin et al., 2013; Verlinden et al., 2013a; Lord et al., 2014).

\subsection{ASSOCIATIONS BETWEEN GAIT DOMAINS AND COGNITION}

Associations between independent cognitive functions were explored with respect to independent gait domains (Figure 1). Individual gait characteristics were mapped onto their respective domains such that relationships are 
explored with respect to broad gait domains. Where possible, studies which outlined their own domains were appropriately matched to the most relevant domain in the model used in this review as individual gait characteristic associations were mainly not reported. In addition, the strongest statistical analysis has been reported for each study (e.g. if the analysis included consideration of covariates). Tables 2, 3, 4 and 5 summarises the findings into associations for each cohort which are colour coded to show whether an association was found (green) or not (red). Tables 6, 7, 8 and 9 provide further details on each individual study. Figures 3 and 4 complete the schema map of associations for cross-sectional (Figure 3) and longitudinal studies (Figure 4).

\subsubsection{PACE}

Pace was the most frequently assessed gait variable in all three cohorts (Lord and Menz, 2002; Sheridan et al., 2003; Rochester et al., 2004; Ble et al., 2005; Hausdorff et al., 2005; Rochester et al., 2005; Yogev et al., 2005; Holtzer et al., 2006; Fitzpatrick et al., 2007; Hollman et al., 2007; Auyeung et al., 2008; Duff et al., 2008; Persad et al., 2008; Rochester et al., 2008; van lersel et al., 2008; Deshpande et al., 2009; Gillain et al., 2009; Allali et al., 2010b; Atkinson et al., 2010; Lord et al., 2010; Maquet et al., 2010; Watson et al., 2010; Lamoth et al., 2011; McGough et al., 2011; Amboni et al., 2012; Beauchet et al., 2012; Bramell-Risberg et al., 2012; Donoghue et al., 2012; Holtzer et al., 2012; ljmker and Lamoth, 2012; Kaye et al., 2012; Muir et al., 2012; Beauchet et al., 2013; Lord et al., 2013; Martin et al., 2013; Smulders et al., 2013; Verlinden et al., 2013a; Wild et al., 2013; Lord et al., 2014; Xu et al., 2014). In addition, a number of studies assessed specific gait characteristics that loaded onto the pace domain (Sheridan et al., 2003; Rochester et al., 2004; Hausdorff et al., 2005; Yogev et al., 2005; Holtzer et al., 2006; Hollman et al., 2007; van lersel et al., 2008; Gillain et al., 2009; Allali et al., 2010b; Maquet et al., 2010; Lamoth et al., 2011; Amboni et al., 2012; Beauchet et al., 2012; Coelho et al., 2012; Holtzer et al., 2012; ljmker and Lamoth, 2012; Muir et al., 2012; Beauchet et al., 2013; Lord et al., 2013; Martin et al., 2013; Verlinden et al., 2013a; Lord et al., 2014) (Figure 1). In 
OA, associations were evident between pace and attention as shown by 7 of 7 studies (Holtzer et al., 2006; Duff et al., 2008; Watson et al., 2010; Holtzer et al., 2012; Kaye et al., 2012; Lord et al., 2013; Martin et al., 2013), executive function as shown by 8 of 12 studies (Hausdorff et al., 2005; Holtzer et al., 2006; Watson et al., 2010; Beauchet et al., 2012; Donoghue et al., 2012; Holtzer et al., 2012; Martin et al., 2013; Verlinden et al., 2013a), processing speed as shown by 5 of 6 studies (Holtzer et al., 2006; Watson et al., 2010; Donoghue et al., 2012; Kaye et al., 2012; Martin et al., 2013), language as shown by 3 of 3 studies (Holtzer et al., 2006; Duff et al., 2008; Holtzer et al., 2012) and visuospatial skills as shown by 2 of 3 studies (Duff et al., 2008; Kaye et al., 2012). In OA no association was evident between pace and global cognition (Hausdorff et al., 2005; Fitzpatrick et al., 2007; Hollman et al., 2007; Irani et al., 2007; Atkinson et al., 2010; Bramell-Risberg et al., 2012; Lord et al., 2013) and pace and memory (Hausdorff et al., 2005; van lersel et al., 2008; Kaye et al., 2012; Lord et al., 2013; Martin et al., 2013; Verlinden et al., 2013a). In the $\mathrm{Cl}$ cohort pace was assessed in nine studies with AD participants (Sheridan et al., 2003; Persad et al., 2008; Gillain et al., 2009; Allali et al., 2010a; Maquet et al., 2010; Lamoth et al., 2011; Coelho et al., 2012; ljmker and Lamoth, 2012; Muir et al., 2012; Beauchet et al., 2013), two with FTD (Allali et al., 2010a; ljmker and Lamoth, 2012), one with $\mathrm{Cl}$ (Auyeung et al., 2008) and three with MCI (Gillain et al., 2009; Muir et al., 2012; Beauchet et al., 2013). Slower gait speed was associated with AD (Sheridan et al., 2003; Persad et al., 2008; Gillain et al., 2009; Maquet et al., 2010; Coelho et al., 2012; ljmker and Lamoth, 2012), FTD (Allali et al., 2010a; ljmker and Lamoth, 2012) and Cl (Auyeung et al., 2008) but not MCI (Gillain et al., 2009; Muir et al., 2012; Beauchet et al., 2013). In the $\mathrm{Cl}$ cohort, an association between pace and executive function was supported by 2 of 3 studies (Persad et al., 2008; McGough et al., 2011). Only one study associated pace with global cognition and attention (Maquet et al., 2010). In PD, an association was evident between pace and attention with 2 of 3 studies obtaining this result (Lord et al., 2010; Lord et al., 2014). Evidence was inconclusive for pace and executive function with 5 studies finding an association (Rochester et al., 2004; Rochester et al., 2005; Yogev et al., 2005; Smulders et al., 2013; Xu et al., 2014) and 5 not (Rochester et 
al., 2008; Lord et al., 2010; Amboni et al., 2012; Wild et al., 2013; Lord et al., 2014), pace and visuospatial with one study finding an association (Amboni et al., 2012) and one study not (Lord et al., 2014) and pace and memory with one study finding an association (Lord et al., 2014) and one study not (Amboni et al., 2012). There was no association between pace and global cognition for PD.

\subsubsection{VARIABILITY}

Characteristics of gait variability including step velocity variability, step length variability and step width variability (Figure 1) were comprehensively assessed in OA (van lersel et al., 2008; Holtzer et al., 2012; Kaye et al., 2012; Lord et al., 2013; Martin et al., 2013; Verlinden et al., 2013a) but were limited in PD (Amboni et al., 2012; Lord et al., 2014) and were not studied in $\mathrm{Cl}$. In OA no consistent associations were evident with any of the cognitive domains (van lersel et al., 2008; Holtzer et al., 2012; Kaye et al., 2012; Lord et al., 2013; Martin et al., 2013). In PD only two studies explored variability and cognition (Amboni et al., 2012; Lord et al., 2014). One study assessed global cognition for which an association was found (Lord et al., 2014). Evidence was inconclusive for visuospatial ability with one study finding an association (Amboni et al., 2012) and the other study refuting these findings (Lord et al., 2014). No associations were found with executive function, attention or memory in PD.

\subsubsection{RHYTHM}

Characteristics of rhythm including step time, step swing time and step stance time (Figure 1) were assessed throughout the three cohorts (Rochester et al., 2004; Hausdorff et al., 2005; Gillain et al., 2009; Allali et al., 2010a; Maquet et al., 2010; Lamoth et al., 2011; Coelho et al., 2012; Holtzer et al., 2012; ljmker and Lamoth, 2012; Muir et al., 2012; Lord et al., 2013; Martin et al., 2013; Verlinden et al., 2013a; Wild et al., 2013; Lord et al., 2014). Five studies in OA assessed rhythm (Hausdorff et al., 2005; Holtzer et al., 2012; Lord et al., 2013; Martin et al., 2013; Verlinden et al., 
2013a) providing evidence for an association with processing speed (Martin et al., 2013; Verlinden et al., 2013a) but no other domains. Rhythm was assessed in AD (Gillain et al., 2009; Maquet et al., 2010; Lamoth et al., 2011; Coelho et al., 2012; ljmker and Lamoth, 2012; Muir et al., 2012), FTD (ljmker and Lamoth, 2012) and MCI (Gillain et al., 2009; Maquet et al., 2010; Muir et al., 2012) with only inconclusive evidence associating rhythm deficit in FTD (ljmker and Lamoth, 2012) and MCl (Gillain et al., 2009; Maquet et al., 2010). In the $\mathrm{Cl}$ group, only one study assessed global cognition for which an association was found (Maquet et al., 2010). There was no evidence for an association between rhythm and attention (Maquet et al., 2010). In PD, rhythm was measured by five studies (Rochester et al., 2004; Amboni et al., 2012; Wild et al., 2013; Lord et al., 2014) with no evidence for associations with cognition. One study which sub-grouped motor phenotype (Lord et al., 2014) associated rhythm and executive function in the postural instability/gait difficulty (PIGD) phenotype only.

\subsubsection{ASYMMETRY}

Asymmetry was the least frequently tested gait variable with characteristics of step time asymmetry, step swing asymmetry and step stance asymmetry (Lord et al., 2013; Lord et al., 2014) assessed in OA and PD only (Figure 1). There were no associations with cognition.

\subsubsection{POSTURAL CONTROL}

Postural control characteristics of step width and step length asymmetry (Figure 1) were assessed by a total of seven studies (van lersel et al., 2008; Amboni et al., 2012; Lord et al., 2013; Martin et al., 2013; Verlinden et al., 2013a; Lord et al., 2014) throughout the cohorts. In OA one study assessed postural control and visuospatial function, and reported a significant association (Martin et al., 2013). Evidence was inconclusive in OA for an association with executive function, attention and processing speed with 2 of 4 studies (Lord et al., 2013; Martin et al., 2013), 1 of 2 studies (Martin et al., 2013) and 1 of 2 (Martin et al., 2013) studies observing associations 
respectively. No association was evident in OA for postural control for global cognition (Lord et al., 2013) and memory (van lersel et al., 2008; Lord et al., 2013; Martin et al., 2013; Verlinden et al., 2013a). There was no evidence for associations in the $\mathrm{Cl}$ cohort. Two studies observed postural control in PD (Amboni et al., 2012; Lord et al., 2014) with inconclusive evidence for associations with memory (Lord et al., 2014) and visuospatial (Amboni et al., 2012). In PD there were no associations with global cognition (Amboni et al., 2012; Lord et al., 2014), executive function (Amboni et al., 2012; Lord et al., 2014) or attention (Lord et al., 2014).

\subsection{LONGITUDINAL STUDIES OF THE GAIT-COGNITION RELATIONSHIP}

Twelve studies investigated longitudinal relationships between gait and cognition (Marquis et al., 2002; Alfaro-Acha et al., 2007; Atkinson et al., 2007; Inzitari et al., 2007; Verghese et al., 2007; Deshpande et al., 2009; Atkinson et al., 2010; Buracchio et al., 2010; Watson et al., 2010; Auyeung et al., 2011; Dodge et al., 2012; Taniguchi et al., 2012). Eleven studies assessed healthy OA at baseline (Marquis et al., 2002; Alfaro-Acha et al., 2007; Atkinson et al., 2007; Inzitari et al., 2007; Verghese et al., 2007; Deshpande et al., 2009; Atkinson et al., 2010; Buracchio et al., 2010; Watson et al., 2010; Auyeung et al., 2011; Taniguchi et al., 2012). One study observed three cohorts at different stages of $\mathrm{MCl}$ (Dodge et al., 2012). 9 of the 12 studies assessed gait as a predictor for cognitive decline (Marquis et al., 2002; Alfaro-Acha et al., 2007; Inzitari et al., 2007; Verghese et al., 2007; Auyeung et al., 2008; Deshpande et al., 2009; Buracchio et al., 2010; Dodge et al., 2012; Taniguchi et al., 2012), 2 of 12 assessed cognition as a predictor for gait decline (Atkinson et al., 2007; Watson et al., 2010) and 1 of 12 studied the decline of gait and cognition simultaneously (Atkinson et al., 2010).

\subsubsection{GAIT AS A PREDICTOR FOR COGNITIVE DECLINE}


All nine studies assessing gait as a predictor measured pace. Evidence was strong for pace as a predictor for global cognition as shown by 7 of 9 studies (Marquis et al., 2002; Alfaro-Acha et al., 2007; Verghese et al., 2007; Buracchio et al., 2010; Auyeung et al., 2011; Dodge et al., 2012; Taniguchi et al., 2012) with two studies refuting these findings (Deshpande et al., 2009; Atkinson et al., 2010).Two studies observed cognitive domains (Inzitari et al., 2007; Verghese et al., 2007). Pace predicted a decline in executive function (Verghese et al., 2007) and processing speed (Inzitari et al., 2007). Evidence was inconclusive for decline in attention with one study finding this (Inzitari et al., 2007) and one not (Verghese et al., 2007). Pace was not found to be a predictor of memory decline (Verghese et al., 2007). One study assessed variability of gait (Verghese et al., 2007) which predicted dementia onset but not domains of global cognition, attention, executive function or memory. Two studies assessed rhythm of gait (Verghese et al., 2007; Taniguchi et al., 2012). An association between rhythm and decline in memory was identified by one study (Verghese et al., 2007). Evidence was inconclusive for rhythm as a predictor of global cognitive decline (Verghese et al., 2007; Taniguchi et al., 2012) with one study identifying rhythm as a risk factor for dementia onset (Verghese et al., 2007). No links were found between rhythm and decline in executive function or attention (Verghese et al., 2007).

\subsubsection{COGNITION AS A PREDICTOR FOR GAIT DECLINE}

All three studies assessed pace only. Evidence suggested that global cognition (Atkinson et al., 2007; Watson et al., 2010), executive function (Atkinson et al., 2007; Watson et al., 2010) and memory (Watson et al., 2010) predicted a decline in pace. There were no evidence for processing speed (Watson et al., 2010) or attention (Watson et al., 2010) as predictors of decline in pace.

\section{DISCUSSION}


To our knowledge this is the first structured review to summarise the relationship between single task gait and cognition in older adults with and without cognitive impairment, and in PD. Key findings from this structured review are that for all groups the pace domain of gait (driven predominantly by gait speed) is associated with a broad range of cognitive functions but also selectively associated with executive attention. Gait speed is also a strong predictor of cognitive decline in OA, however there is also some evidence of reverse causality. Other relationships are emerging but restricted by a limited scope of gait and cognitive outcomes as well as methodological inconsistencies. Results from this study partly confirm our hypotheses. Independent gait characteristics relate to discrete cognitive functions and the pattern of association varies as a function of pathology and age. This specificity will help inform our understanding of co-incident pathology and shared neural networks, and help identify the pattern of change for each over time. In all three groups the pace domain of gait was also associated almost universally with cognitive measures. Although less discrete, this sensitivity provides a basis for understanding the broader relationship between gait and cognition, and provides a platform for more specific inquiry.

\subsection{GAIT AND COGNITION: A GLOBAL RELATIONSHIP}

This review identified a broad range of cognitive correlates for gait. Of all gait characteristics measured, those from the pace domain (particularly gait speed) yielded the strongest relationships. Reasons for this are twofold. With one exception, gait speed was universally measured in all studies which increased the likelihood of chance findings and dominated the results. Secondly, of the 16 gait characteristics reflected in the gait model, gait speed is the most sensitive and least specific metric. It reflects global gait impairment but does not inform about the underlying cause of that impairment. Gait speed may be considered 'the final common expression' of gait, and associations with cognition are therefore likely to be more evident for this global measure.

\subsection{GAIT AND COGNITION: A SELECTIVE RELATIONSHIP}


A number of studies adopted a broader approach to measurement where selective associations became evident (Verghese et al., 2007; Verlinden et al., 2013a; Lord et al., 2014). Assessments were particularly limited in pathological cohorts and in addition, sample sizes tended to be small, albeit with some exceptions (Rochester et al., 2008; McGough et al., 2011; Amboni et al., 2012; Smulders et al., 2013; Lord et al., 2014). Despite limitations, subtle emergent associations have been mapped that appear specific to pathology which are discussed below. These findings contribute to our understanding of underlying pathology and the mechanisms that underpin cognitive and gait functions with respect to that pathology. What is evident is that common neural substrates for gait and cognition emerge which may differ according to age and pathology. This knowledge will ultimately lead to refinement of diagnostics and development of novel therapeutics.

Evidence associating pace with attention and executive function (considered here as the executive attention domain (Perry and Hodges, 1999; WoodruffPak and Papka, 1999; Emre et al., 2007; Wild et al., 2013)) was demonstrated in all three groups. This was most evident in OA as demonstrated by large number of high quality studies. In disease cohorts this association was not as strong, due to a smaller number of studies which were more varied in quality and therefore must be interpreted with more caution. Lesion (Wilkins et al., 1987) and imaging studies (Collette et al., 2006) implicate the prefrontal cortex (PFc) as the site for executive attention which initiates purposeful, goal directed behaviours essential to daily living (Criado et al., 1997; Perry and Hodges, 1999) . In addition, the PFc drives executive attention processes during locomotion to modulate gait (Malouin et al., 2003; Koenraadt et al., 2014). In normal ageing, executive attention declines (Gunning-Dixon and Raz, 2000; Grieve et al., 2007) with more pronounced deficits occurring in neurological disorders including PD (Emre, 2003) and AD (Perry and Hodges, 1999). Decline in PFc function is associated with increased white matter lesions in older adults and pathology (Bartzokis et al., 2003; Resnick et al., 2003) resulting in deficits in velocity and step length of gait (Nadkarni et al., 2009; de Laat et al., 2012). An important caveat to interpretation of imaging data is that not all brain 
structures potentially implicated in gait and cognitive processing are imaged, and this may lead to an incomplete view. The notion of shared cognitive and gait neural substrates is supported elsewhere. For example, in PD, dopaminergic neuronal loss of the substantia nigra impacts on the PFC via a complex network of neuronal pathways and connections (Gotham et al., 1988). This loss attenuates cognitive resource in people with PD, which in turn compromises the ability to cognitively compensate for gait deficit (Yogev-Seligmann et al., 2008). Other neurotransmitters are implicated in this relationship. For example, acetyl-choline (Ach) mediates attentional processes of the PFC (Yarnall et al., 2011) which is associated with a slower gait speed (Rochester et al., 2012). Preliminary results report beneficial effects of Rivastigmine, an acetylcholinesterase inhibitor, on reducing step time variability in people with PD (Henderson et al., 2015), considered a proxy of falls. Thus, age-related degeneration in white matter may elicit an associated decline in pace and executive attention, predominantly due to cholinergic burden. This burden may be exacerbated in disease such as dementia and PD. Development of cognitive enhancement therapies is likely to expand as our understanding of the effect of cognitive processes on gait becomes more refined.

Specific to PD pathology but not dementia, postural control and variability were both associated with cognition. Postural control is an essential component of gait, and similarly to pace, cortical networks are used to modulate postural control (Kelly et al., 2015) via activation of executiveattention networks (Lord et al., 2013; Martin et al., 2013). The ability to regulate postural control is compromised by white matter pathology in these and other cortical networks (de Laat et al., 2011; Rosano et al., 2012). Executive-attention also mediates visuo-spatial function which is critical to postural control (Suarez et al., 2011). This association of visuo-spatial function was noted in older adults (Martin et al., 2013), although this was reported only in one study. However previous literature has identified an association of visual performance and measures of balance in older people (Brach et al., 2008). This relationship may be exacerbated, in people with PD with freezing of gait (FOG), who perform worse on tests of visuospatial ability 
compared to non-FOG (Cowie et al., 2010) possibly due to decreased grey matter in posterior cortical areas (Tessitore et al., 2012). Evidence of association for postural control and memory was contradictory for the two studies that examined these features (Amboni et al., 2012; Lord et al., 2014). Both studies used valid tests as recognised by the PDD movement disorder task force (Dubois et al., 2007), Lords' study showed an association used working memory (forward digit span) (Lord et al., 2014) in contrast to Amboni's study which did not show an association used the Rey Auditory Verbal Learning Test (RAVLT) (Amboni et al., 2012). Important to note is the association in Lord's study was driven by the PIGD phenotype (Lord et al., 2014), which further sensitised results. Associations for global cognition and visuospatial ability with variability were also evident for people with PD but once again were contradictory. A positive association was found with global cognition using the MoCA (Lord et al., 2014) but not the MMSE (Amboni et al., 2012) essentially because the MoCA is a more sensitive test of cognition in those with PD (Zadikoff et al., 2008). Similarly for visuospatial outcomes, an association was found when a rigorous visuospatial assessment battery was used, thus optimising neural correlates (Lord et al., 2014). However, once again these results were in the FOG cohort. The same results were not replicated in $O A$ suggesting the relationship is mediated by visuospatial difficulties in PD and not normal ageing. However, the data emerges from a small number of studies and, although promising, will need to be explored in future research.

For participants with cognitive impairment and dementia an association emerged between cognitive function and the rhythm domain of gait, possibly mediated by the hippocampus which is affected by cognitive decline and FTD (Fellgiebel et al., 2004; Franceschi et al., 2005). The hippocampus plays an important role in motor and gait tasks (Bland and Oddie, 2001; Paylor et al., 2001; Malouin et al., 2003), and is key to effective spatial navigation (Epstein, 2008). However, this data should be interpreted cautiously because AD and FTD groups were combined, and this may have confounded results. More surprisingly, rhythm was also associated with executive function in PIGD phenotype of PD (Lord et al., 2014). People with 
PD who present with the PIGD phenotype deteriorate at a faster rate in both gait and cognitive function and are at a higher risk of developing dementia than those with the tremor-dominant phenotype (Burn et al., 2006) making the association more sensitive. Unexpectedly, rhythm was also associated with processing speed in older adults (Martin et al., 2013; Verlinden et al., 2013a). The authors suggested this may be linked to the velocity aspect of rhythm and to the timing nature of cognitive assessments (Martin et al., 2013; Verlinden et al., 2013a). In addition, cognitive tests of processing speed may overlap with executive-attentional elements (Donoghue et al., 2012) which may well have contributed to this association. Although rhythm is considered a 'rudimentary' characteristic of gait (Lord et al., 2013) controlled by subcortical brain regions including the brain stem and spinal cord (Taniguchi et al., 2012), in response to pathology and ageing it may become more cortically mediated.

We did not find any reported associations between the asymmetry domain of gait and cognition, although only four studies assessed asymmetry across all cohorts (Gillain et al., 2009; Maquet et al., 2010; Lord et al., 2013; Lord et al., 2014). Asymmetry comprises both spatial and temporal features of gait. Spatial asymmetry is more likely to be associated with cognitive function given its relationship with step length which, as evidenced by this review, is frontally mediated (Martin et al., 2013). In contrast, temporal features of asymmetry are driven subcortically (Barrière et al., 2008) and cognitive correlates are therefore less likely. However, the single study in early PD that examined these features separately did not find a relationship between spatial asymmetry and cognition. Although spatial asymmetry was significantly worse in PD compared to controls, the threshold for cognitive deficit to provide a signal with asymmetry was not reached.

\subsection{GAIT AS A PREDICTOR OF COGNITIVE DECLINE}

This review provides robust evidence of the capacity of gait to predict cognitive decline, with a number of large, community based studies in older adults supporting this view (Table 5). Risk of developing vascular dementia 
or decline in executive attention is predicted by impairment in the pace domain of gait (Gootjes et al., 2004; Verghese et al., 2007) signalling that gait is sensitive to early changes in $\mathrm{WMH}$. This finding is also evident in older adults (Nadkarni et al., 2009) suggesting sensitivity of gait to more subtle cognitive burden. Studies that take a nuanced approach have found specific associations (Verghese et al., 2007). For example, Verghese and colleagues reported that change over time in gait rhythm was a predictor of memory decline and risk of future dementia in healthy older adults (Verghese et al., 2007) which may reflect early pathology in the hippocampus (Braak and Braak, 1997).

The question of reverse causality however cannot be ignored. Several studies (although smaller in number) report that cognition was predictive of decline in the pace domain of gait (Atkinson et al., 2007; Watson et al., 2010). These findings further indicate the intricate relationship between gait and cognition and argue for a comprehensive and sensitive battery of testing for both in order to tease out their relative burden and temporal course. Figure 5 explores this complexity in more detail. It is plausible, for example, for cognitive and gait deficit to co-inside in response to ageing and the time course of decline to occur in parallel or for one to precede the other (Tabbarah et al., 2002; Gale et al., 2014)(Figure 5, concept 1 \& 2). By contrast, this is less likely to be the case for pathology where different pathophysiological substrates define the initial magnitude and direction of change, and their putative course (Figure 5, concept 4). In the absence of data we are left to speculate and future research will examine these questions in greater depth and discern these complex processes. No longitudinal studies on the relationship between gait and cognition have been conducted in PD, and the field is open at this stage to interpretation. Based on current evidence (Lord et al., 2014), we speculate that for people with PD, decline in cognition and development of dementia will be predicted by frontal and pre-frontal mechanisms that manifest as deficits in the pace domain of gait (Figure 5, concept $3 \& 4$ ).

The time course of the relationships between gait and cognition is likely to be variable and disease-specific, although there is limited evidence to support 
this. Most cross sectional studies in established $A D$ report an association with pace but not rhythm (Sheridan et al., 2003; Gillain et al., 2009; Allali et al., 2010a; Maquet et al., 2010; Coelho et al., 2012; ljmker and Lamoth, 2012; Muir et al., 2012) suggesting as disease progresses cortical influences on gait may become more dominant (Braak and Braak, 1995). One longitudinal study supported an association between early change in gait variability and global cognitive decline, similar to cross sectional findings (Verlinden et al., 2013a; Lord et al., 2014). However, further work is required to examine these features.

\subsection{RECOMMENDATIONS AND FUTURE WORK}

The key recommendation from this review is that future studies need to incorporate comprehensive batteries of gait and cognition in order to robustly identify associations. Use of standardised protocols will ensure consistency and aid interpretation. Advances in technology via use of validated body worn senses mean that gait can now be measured in home and community environments rather than the laboratory (Godfrey et al., 2014). Not only do sensors provide a simple and cost-effective method of data collection, their use also facilitates measurement in naturalistic environments which reflect habitual gait patterns. The cognitive correlates of naturalistic gait may be different what we have reported here (Hagler et al., 2010) and this is an exciting field of future research.

Limitations to this review include use of a model of gait we were familiar with to structure our analysis. We may have found more associations if we had included more gait characteristics or used a different model. However, we were confident in selecting the model because it has been validated in PD and older adults, and it allowed for a more structured and robust interpretation. Nevertheless, it is important to recognise the interdependence of both gait characteristics (and therefore gait domains), and cognitive functions which also overlap. This has the potential to obfuscate findings and challenge interpretation. Secondly, a quality assessment tool was not used within this structured review which may have limited interpretation. Early on our review process clearly indicated predominance of measurement for the pace domain of gait to the exclusion of other domains. We felt this would bias results if a full systematic review with grading for study quality had been 
undertaken. Our findings highlight the need for a more robust methodological approach in this field, which warrants further investigation. Finally, dual task conditions were not reviewed here because we were interested in habitual gait performance. Also, dual task protocols vary widely and findings are inconsistent (Kelly et al., 2015). Methodological issues include diversity of concurrent tasks, inadequate control of baseline task demand, and a varied approach to calculating and interpreting dual task interference (Rochester et al., 2014). However, not including dual task studies may have attenuated findings. Studies report an increase in gait variability (Hollman et al., 2007), rhythm (Yogev et al., 2005) and asymmetry (Yogev et al., 2007) in OA and PD under dual task conditions, reflecting an inability to compensate cognitively for gait deficit. Selective associations with cognitive outcomes have been reported, but it is beyond the scope of this review to comment on these.

In conclusion, this review has systematically examined and reported on a large number of studies concerning the relationship between gait and cognition which is firmly established. Future research will consolidate findings and procure a more nuanced understanding of this important relationship.

\section{Conflicts of Interest}

No conflicts of interest are declared

\section{Acknowledgements}

This research is supported by the National Institute for Health Research (NIHR) Newcastle Biomedical Research Unit (BRU) and centre (BRC) based at Newcastle upon Tyne Hospitals NHS Foundation Trust and Newcastle University. The research was also supported by NIHR Newcastle CRF Infrastructure funding. The views expressed are those of the authors and not necessarily those of the NHS, the NIHR or the Department of Health. 


\section{References}

Alfaro-Acha, A., Al Snih, S., Raji, M.A., Markides, K.S. and Ottenbacher, K.J. (2007) 'Does 8-foot walk time predict cognitive decline in older Mexicans Americans?', Journal of the American Geriatrics Society, 55(2), pp. 245-51. Allali, G., Dubois, B., Assal, F., Lallart, E., de Souza, L.C., Bertoux, M., Annweiler, C., Herrmann, F.R., Levy, R. and Beauchet, O. (2010a) 'Frontotemporal dementia: Pathology of gait?', Movement Disorders, 25(6), pp. 731-737.

Allali, G., van der Meulen, M. and Assal, F. (2010b) 'Gait and cognition: The impact of executive function', Schweizer Archiv fur Neurologie und Psychiatrie, 161(6), pp. 195-199.

Amboni, M., Barone, P., luppariello, L., Lista, I., Tranfaglia, R., Fasano, A., Picillo, M., Vitale, C., Santangelo, G. and Agosti, V. (2012) 'Gait patterns in Parkinsonian patients with or without mild cognitive impairment', Movement Disorders, 27(12), pp. 1536-1543.

Atkinson, H.H., Rapp, S.R., Williamson, J.D., Lovato, J., Absher, J.R., Gass, M., Henderson, V.W., Johnson, K.C., Kostis, J.B., Sink, K.M., Mouton, C.P., Ockene, J.K., Stefanick, M.L., Lane, D.S. and Espeland, M.A. (2010) 'The relationship between cognitive function and physical performance in older women: results from the women's health initiative memory study', Journals of Gerontology Series A-Biological Sciences \& Medical Sciences, 65(3), pp. 300-6.

Atkinson, H.H., Rosano, C., Simonsick, E.M., Williamson, J.D., Davis, C., Ambrosius, W.T., Rapp, S.R., Cesari, M., Newman, A.B., Harris, T.B., Rubin, S.M., Yaffe, K., Satterfield, S. and Kritchevsky, S.B. (2007) 'Cognitive function, gait speed decline, and comorbidities: The Health, Aging and Body Composition study', The Journals of Gerontology: Series A: Biological Sciences and Medical Sciences, 8(8), pp. 844-850.

Auyeung, T.W., Kwok, T., Lee, J., Leung, P.C., Leung, J. and Woo, J. (2008) 'Functional decline in cognitive impairment - The relationship between physical and cognitive function', Neuroepidemiology, 31(3), pp. 167-173.

Auyeung, T.W., Lee, J.S., Kwok, T. and Woo, J. (2011) 'Physical frailty predicts future cognitive decline - a four-year prospective study in 2737 
cognitively normal older adults', Journal of Nutrition, Health \& Aging, 15(8), pp. 690-4.

Barrière, G., Leblond, H., Provencher, J. and Rossignol, S. (2008) 'Prominent Role of the Spinal Central Pattern Generator in the Recovery of Locomotion after Partial Spinal Cord Injuries', The Journal of Neuroscience, 28(15), pp. 3976-3987.

Bartzokis, G., Cummings, J.L., Sultzer, D., Henderson, V.W., Nuechterlein, K.H. and Mintz, J. (2003) 'White matter structural integrity in healthy aging adults and patients with alzheimer disease: A magnetic resonance imaging study', Archives of Neurology, 60(3), pp. 393-398.

Beauchet, O., Allali, G., Launay, C., Herrmann, F.R. and Annweiler, C. (2013) 'Gait variability at fast-pace walking speed: A biomarker of mild cognitive impairment?', Journal of Nutrition, Health and Aging, 17(3), pp. 235-239.

Beauchet, O., Annweiler, C., Montero-Odasso, M., Fantino, B., Herrmann, F.R. and Allali, G. (2012) 'Gait control: a specific subdomain of executive function?', Journal of Neuroengineering \& Rehabilitation, 9, p. 12.

Bland, B.H. and Oddie, S.D. (2001) 'Theta band oscillation and synchrony in the hippocampal formation and associated structures: the case for its role in sensorimotor integration', Behavioural Brain Research, 127(1-2), pp. 119136.

Ble, A., Volpato, S., Zuliani, G., Guralnik, J.M., Bandinelli, S., Lauretani, F., Bartali, B., Maraldi, C., Fellin, R. and Ferrucci, L. (2005) 'Executive function correlates with walking speed in older persons: the InCHIANTI study', Journal of the American Geriatrics Society, 53(3), pp. 410-5.

Braak, H. and Braak, E. (1995) 'Staging of alzheimer's disease-related neurofibrillary changes', Neurobiology of Aging, 16(3), pp. 271-278.

Braak, H. and Braak, E. (1997) 'Frequency of Stages of Alzheimer-Related Lesions in Different Age Categories', Neurobiology of Aging, 18(4), pp. 351357.

Brach, J.S., Studenski, S., Perera, S., VanSwearingen, J.M. and Newman, A.B. (2008) 'Stance time and step width variability have unique contributing impairments in older persons', Gait \& Posture, 27(3), pp. 431-439. 
Bramell-Risberg, E., Jarnlo, G.B. and Elmståhl, S. (2012) 'Separate physical tests of lower extremities and postural control are associated with cognitive impairment. Results from the general population study Good Aging in Skåne (GÅS-SNAC)', Clinical Interventions in Aging, 7, pp. 195-205.

Buracchio, T., Dodge, H.H., Howieson, D., Wasserman, D. and Kaye, J. (2010) 'The trajectory of gait speed preceding mild cognitive impairment', Archives of Neurology, 67(8), pp. 980-6.

Burn, D.J., Rowan, E.N., Allan, L.M., Molloy, S., O'Brien, J.T. and McKeith, I.G. (2006) 'Motor subtype and cognitive decline in Parkinson's disease, Parkinson's disease with dementia, and dementia with Lewy bodies', Journal of Neurology, Neurosurgery, and Psychiatry, 77(5), pp. 585-589.

Burton, E.J., McKeith, I.G., Burn, D.J., Williams, E.D. and O'Brien, J.T. (2004) 'Cerebral atrophy in Parkinson's disease with and without dementia: a comparison with Alzheimer's disease, dementia with Lewy bodies and controls', Brain, 127(Pt 4), pp. 791-800.

Callisaya, M.L., Beare, R., Phan, T.G., Blizzard, L., Thrift, A.G., Chen, J. and Srikanth, V.K. (2013) 'Brain Structural Change and Gait Decline: A Longitudinal Population-Based Study', Journal of the American Geriatrics Society, 61(7), pp. 1074-1079.

Coelho, F.G., Stella, F., de Andrade, L.P., Barbieri, F.A., Santos-Galduroz, R.F., Gobbi, S., Costa, J.L. and Gobbi, L.T. (2012) 'Gait and risk of falls associated with frontal cognitive functions at different stages of Alzheimer's disease', Aging Neuropsychology \& Cognition, 19(5), pp. 644-56.

Collette, F., Hogge, M., Salmon, E. and Van der Linden, M. (2006) 'Exploration of the neural substrates of executive functioning by functional neuroimaging', Neuroscience, 139(1), pp. 209-21.

Cowie, D., Limousin, P., Peters, A. and Day, B.L. (2010) 'Insights into the neural control of locomotion from walking through doorways in Parkinson's disease', Neuropsychologia, 48(9), pp. 2750-2757.

Criado, J.M., Heredia, M., Riolobos, A.S., Yajeya, J. and de la Fuente, A. (1997) 'Electrophysiological study of prefrontal neurones of cats during a motor task', Pflügers Archiv, 434(1), pp. 91-96.

de Laat, K.F., Reid, A.T., Grim, D.C., Evans, A.C., Kötter, R., van Norden, A.G.W. and de Leeuw, F.-E. (2012) 'Cortical thickness is associated with gait 
disturbances in cerebral small vessel disease', Neurolmage, 59(2), pp. 14781484.

de Laat, K.F., van Norden, A.G., Gons, R.A., van Oudheusden, L.J., van Uden, I.W., Norris, D.G., Zwiers, M.P. and de Leeuw, F.E. (2011) 'Diffusion tensor imaging and gait in elderly persons with cerebral small vessel disease', Stroke, 42(2), pp. 373-9.

Deshpande, N., Metter, E.J., Bandinelli, S., Guralnik, J. and Ferrucci, L. (2009) 'Gait speed under varied challenges and cognitive decline in older persons: a prospective study', Age \& Ageing, 38(5), pp. 509-14.

Dodge, H., Mattek, N., Austin, D., Hayes, T. and Kaye, J. (2012) 'In-home walking speeds and variability trajectories associated with mild cognitive impairment', Neurology, 78(24), pp. 1946-1952.

Donoghue, O.A., Horgan, N., Savva, G.M., Cronin, H., O'Regan, C. and Kenny, R.A. (2012) 'Association between timed up-and-go and memory, executive function, and processing speed', Journal of the American Geriatrics Society, 60(9), pp. 1681-1686.

Dubois, B., Burn, D., Goetz, C., Aarsland, D., Brown, R.G., Broe, G.A., Dickson, D., Duyckaerts, C., Cummings, J., Gauthier, S., Korczyn, A., Lees, A., Levy, R., Litvan, I., Mizuno, Y., McKeith, I.G., Olanow, C.W., Poewe, W., Sampaio, C., Tolosa, E. and Emre, M. (2007) 'Diagnostic procedures for Parkinson's disease dementia: Recommendations from the movement disorder society task force', Movement Disorders, 22(16), pp. 2314-2324.

Duff, K., Mold, J.W. and Roberts, M.M. (2008) 'Walking speed and global cognition: results from the OKLAHOMA Study', Aging Neuropsychology \& Cognition, 15(1), pp. 31-9.

Emre, M. (2003) 'Dementia associated with Parkinson's disease', The Lancet Neurology, 2(4), pp. 229-237.

Emre, M., Aarsland, D., Brown, R., Burn, D.J., Duyckaerts, C., Mizuno, Y., Broe, G.A., Cummings, J., Dickson, D.W., Gauthier, S., Goldman, J., Goetz, C., Korczyn, A., Lees, A., Levy, R., Litvan, I., McKeith, I., Olanow, W., Poewe, W., Quinn, N., Sampaio, C., Tolosa, E. and Dubois, B. (2007) 'Clinical diagnostic criteria for dementia associated with Parkinson's disease', Mov Disord, 22(12), pp. 1689-707; quiz 1837. 
Epstein, R.A. (2008) 'Parahippocampal and retrosplenial contributions to human spatial navigation', Trends in Cognitive Sciences, 12(10), pp. 388396.

Fellgiebel, A., Wille, P., Müller, M.J., Winterer, G., Scheurich, A., Vucurevic, G., Schmidt, L.G. and Stoeter, P. (2004) 'Ultrastructural Hippocampal and White Matter Alterations in Mild Cognitive Impairment: A Diffusion Tensor Imaging Study', Dementia and Geriatric Cognitive Disorders, 18(1), pp. 101108.

Fitzpatrick, A.L., Buchanan, C.K., Nahin, R.L., Dekosky, S.T., Atkinson, H.H., Carlson, M.C., Williamson, J.D. and Ginkgo Evaluation of Memory Study, I. (2007) 'Associations of gait speed and other measures of physical function with cognition in a healthy cohort of elderly persons', Journals of Gerontology Series A-Biological Sciences \& Medical Sciences, 62(11), pp. 1244-51.

Franceschi, M., Anchisi, D., Pelati, O., Zuffi, M., Matarrese, M., Moresco, R.M., Fazio, F. and Perani, D. (2005) 'Glucose metabolism and serotonin receptors in the frontotemporal lobe degeneration', Annals of Neurology, 57(2), pp. 216-225.

Gale, C., Allerhand, M., Sayer, A., Cooper, C. and Deary, I. (2014) 'The dynamic relationship between cognitive function and walking speed: the English Longitudinal Study of Ageing', AGE, 36(4), pp. 1-11.

Gillain, S., Warzee, E., Lekeu, F., Wojtasik, V., Maquet, D., Croisier, J.L., Salmon, E. and Petermans, J. (2009) 'The value of instrumental gait analysis in elderly healthy, $\mathrm{MCl}$ or Alzheimer's disease subjects and a comparison with other clinical tests used in single and dual-task conditions', Annals of Physical \& Rehabilitation Medicine, 52(6), pp. 453-74.

Godfrey, A., Del Din, S., Barry, G., Mathers, J.C. and Rochester, L. (2014) Engineering in Medicine and Biology Society (EMBC), 2014 36th Annual International Conference of the IEEE. 26-30 Aug. 2014.

Gootjes, L., Teipel, S.J., Zebuhr, Y., Schwarz, R., Leinsinger, G., Scheltens, P., Möller, H.J. and Hampel, H. (2004) 'Regional Distribution of White Matter Hyperintensities in Vascular Dementia, Alzheimer's Disease and Healthy Aging', Dementia and Geriatric Cognitive Disorders, 18(2), pp. 180-188. 
Gotham, A.M., Brown, R.G. and Marsden, C.D. (1988) "Frontal' cognitive function in patients with Parkinson's disease 'on' and 'off' levodopa', Brain, 111 ( Pt 2), pp. 299-321.

Grieve, S.M., Williams, L.M., Paul, R.H., Clark, C.R. and Gordon, E. (2007) 'Cognitive Aging, Executive Function, and Fractional Anisotropy: A Diffusion Tensor MR Imaging Study', American Journal of Neuroradiology, 28(2), pp. 226-235.

Gunning-Dixon, F.M. and Raz, N. (2000) 'The cognitive correlates of white matter abnormalities in normal aging: a quantitative review', Neuropsychology, 14(2), pp. 224-32.

Hagler, S., Austin, D., Hayes, T.L., Kaye, J. and Pavel, M. (2010) 'Unobtrusive and ubiquitous in-home monitoring: a methodology for continuous assessment of gait velocity in elders', IEEE Trans Biomed Eng, 57(4), pp. 813-20.

Hausdorff, J.M., Rios, D.A. and Edelberg, H.K. (2001) 'Gait variability and fall risk in community-living older adults: A 1-year prospective study', Archives of Physical Medicine and Rehabilitation, 82(8), pp. 1050-1056.

Hausdorff, J.M., Yogev, G., Springer, S., Simon, E.S. and Giladi, N. (2005) 'Walking is more like catching than tapping: gait in the elderly as a complex cognitive task', Experimental Brain Research, 164(4), pp. 541-8.

Henderson, E., Lord, S., Brodie, M., Close, J., Lawrence, A., Whone, A. and Ben-Sclomo, Y. (2015) 'The ReSPonD trial: Rivastigmine to stabalise gait in Parkinson's disease. A phase II randomised, double blind, placebo-controlled trial to evaluate the effect of rivastigmine on gait in patients with Parkinson's disease who have fallen', MDS Late-breaking Abstracts, San Diego, CA, USA.

Hollman, J.H., Kovash, F.M., Kubik, J.J. and Linbo, R.A. (2007) 'Age-related differences in spatiotemporal markers of gait stability during dual task walking', Gait \& Posture, 26(1), pp. 113-9.

Hollman, J.H., McDade, E.M. and Petersen, R.C. (2011) 'Normative spatiotemporal gait parameters in older adults', Gait \& Posture, 34(1), pp. 111-118.

Holtzer, R., Epstein, N., Mahoney, J.R., Izzetoglu, M. and Blumen, H.M. (2014) 'Neuroimaging of Mobility in Aging: A Targeted Review', The Journals 
of Gerontology Series A: Biological Sciences and Medical Sciences, 69(11), pp. 1375-1388.

Holtzer, R., Verghese, J., Xue, X. and Lipton, R.B. (2006) 'Cognitive processes related to gait velocity: results from the Einstein Aging Study', Neuropsychology, 20(2), pp. 215-23.

Holtzer, R., Wang, C. and Verghese, J. (2012) 'The Relationship Between Attention and Gait in Aging: Facts and Fallacies', Motor control, 16(1), pp. 64-80.

ljmker, T. and Lamoth, C.J. (2012) 'Gait and cognition: the relationship between gait stability and variability with executive function in persons with and without dementia', Gait \& Posture, 35(1), pp. 126-30.

Inzitari, M., Newman, A.B., Yaffe, K., Boudreau, R., de Rekeneire, N., Shorr, R., Harris, T.B. and Rosano, C. (2007) 'Gait speed predicts decline in attention and psychomotor speed in older adults: the health aging and body composition study', Neuroepidemiology, 29(3-4), pp. 156-62.

Irani, F., Platek, S.M., Bunce, S., Ruocco, A.C. and Chute, D. (2007) 'Functional near infrared spectroscopy (fNIRS): an emerging neuroimaging technology with important applications for the study of brain disorders', Clin Neuropsychol, 21, pp. 9 - 37.

Kaye, J., Mattek, N., Dodge, H., Buracchio, T., Austin, D., Hagler, S., Pavel, M. and Hayes, T. (2012) 'One walk a year to 1000 within a year: continuous in-home unobtrusive gait assessment of older adults', Gait Posture, 35(2), pp. 197-202.

Kelly, V.E., Johnson, C.O., McGough, E.L., Shumway-Cook, A., Horak, F.B., Chung, K.A., Espay, A.J., Revilla, F.J., Devoto, J., Wood-Siverio, C., Factor, S.A., Cholerton, B., Edwards, K.L., Peterson, A.L., Quinn, J.F., Montine, T.J., Zabetian, C.P. and Leverenz, J.B. (2015) 'Association of cognitive domains with postural instability/gait disturbance in Parkinson's disease', Parkinsonism Relat Disord.

Koenraadt, K.L.M., Roelofsen, E.G.J., Duysens, J. and Keijsers, N.L.W. (2014) 'Cortical control of normal gait and precision stepping: An fNIRS study', Neurolmage, 85, Part 1, pp. 415-422.

Lamoth, C.J., Van Deudekom, F.J., Van Campen, J.P., Appels, B.A., De Vries, O.J. and Pijnappels, M. (2011) 'Gait stability and variability measures 
show effects of impaired cognition and dual tasking in frail people', Journal of NeuroEngineering and Rehabilitation, 8(1).

Lord, S., Galna, B., Coleman, S., Yarnall, A., Burn, D. and Rochester, L. (2014) 'Cognition and gait show a selective pattern of association dominated by phenotype in incident Parkinson's disease', Frontiers in Aging Neuroscience, 6.

Lord, S., Galna, B., Verghese, J., Coleman, S., Burn, D. and Rochester, L. (2013) 'Independent domains of gait in older adults and associated motor and nonmotor attributes: validation of a factor analysis approach', Journals of Gerontology Series A-Biological Sciences \& Medical Sciences, 68(7), pp. 820-7.

Lord, S., Rochester, L., Hetherington, V., Allcock, L.M. and Burn, D. (2010) 'Executive dysfunction and attention contribute to gait interference in 'off' state Parkinson's Disease', Gait \& Posture, 31(2), pp. 169-74.

Lord, S.R. and Menz, H.B. (2002) 'Physiologic, psychologic, and health predictors of 6-minute walk performance in older people', Archives of Physical Medicine \& Rehabilitation, 83(7), pp. 907-11.

Malouin, F., Richards, C.L., Jackson, P.L., Dumas, F. and Doyon, J. (2003) 'Brain activations during motor imagery of locomotor-related tasks: a PET study', Hum Brain Mapp, 19(1), pp. 47-62.

Maquet, D., Lekeu, F., Warzee, E., Gillain, S., Wojtasik, V., Salmon, E., Petermans, J. and Croisier, J.L. (2010) 'Gait analysis in elderly adult patients with mild cognitive impairment and patients with mild Alzheimer's disease: simple versus dual task: a preliminary report', Clinical Physiology \& Functional Imaging, 30(1), pp. 51-6.

Marquis, S., Moore, M.M., Howieson, D.B., Sexton, G., Payami, H., Kaye, J.A. and Camicioli, R. (2002) 'Independent predictors of cognitive decline in healthy elderly persons', Archives of Neurology, 59(4), pp. 601-6.

Martin, K.L., Blizzard, L., Wood, A.G., Srikanth, V., Thomson, R., Sanders, L.M. and Callisaya, M.L. (2013) 'Cognitive function, gait, and gait variability in older people: a population-based study', Journals of Gerontology Series ABiological Sciences \& Medical Sciences, 68(6), pp. 726-32.

McGough, E.L., Kelly, V.E., Logsdon, R.G., McCurry, S., Cochrane, B.B., Engel, J.M. and Teri, L. (2011) 'Associations between physical performance 
and executive function in older adults with mild cognitive impairment: Gait speed and the timed "Up \& Go" test', Physical Therapy, 91(8), pp. 11981207.

Mielke, M.M., Roberts, R.O., Savica, R., Cha, R., Drubach, D.I., Christianson, T., Pankratz, V.S., Geda, Y.E., Machulda, M.M. and Ivnik, R.J. (2013) 'Assessing the temporal relationship between cognition and gait: slow gait predicts cognitive decline in the Mayo Clinic Study of Aging', The Journals of Gerontology Series A: Biological Sciences and Medical Sciences, 68(8), pp. 929-937.

Mollenhauer, B., Rochester, L., Chen-Plotkin, A. and Brooks, D. (2014) 'What can biomarkers tell us about cognition in Parkinson's disease?', Movement Disorders, 29(5), pp. 622-633.

Muir, S.W., Speechley, M., Wells, J., Borrie, M., Gopaul, K. and MonteroOdasso, M. (2012) 'Gait assessment in mild cognitive impairment and Alzheimer's disease: the effect of dual-task challenges across the cognitive spectrum', Gait \& Posture, 35(1), pp. 96-100.

Nadkarni, N.K., Mcllroy, W.E., Mawji, E. and Black, S.E. (2009) 'Gait and Subcortical Hyperintensities in Mild Alzheimer's Disease and Aging', Dementia and Geriatric Cognitive Disorders, 28(4), pp. 295-301.

Paylor, R., Zhao, Y., Libbey, M., Westphal, H. and Crawley, J.N. (2001) 'Learning impairments and motor dysfunctions in adult Lhx5-deficient mice displaying hippocampal disorganization', Physiology \& Behavior, 73(5), pp. 781-792.

Perry, R.J. and Hodges, J.R. (1999) 'Attention and executive deficits in Alzheimer's disease. A critical review', Brain, 122 ( Pt 3), pp. 383-404.

Persad, C.C., Jones, J.L., Ashton-Miller, J.A., Alexander, N.B. and Giordani, B. (2008) 'Executive function and gait in older adults with cognitive impairment', Journals of Gerontology Series A-Biological Sciences \& Medical Sciences, 63(12), pp. 1350-5.

Resnick, S.M., Pham, D.L., Kraut, M.A., Zonderman, A.B. and Davatzikos, C. (2003) 'Longitudinal Magnetic Resonance Imaging Studies of Older Adults: A Shrinking Brain', The Journal of Neuroscience, 23(8), pp. 3295-3301. 
Rochester, L., Galna, B., Lord, S. and Burn, D. (2014) 'The nature of dualtask interference during gait in incident Parkinson's disease', Neuroscience, 265(0), pp. 83-94.

Rochester, L., Hetherington, V., Jones, D., Nieuwboer, A., Willems, A.M., Kwakkel, G. and Van Wegen, E. (2004) 'Attending to the task: interference effects of functional tasks on walking in Parkinson's disease and the roles of cognition, depression, fatigue, and balance', Archives of Physical Medicine \& Rehabilitation, 85(10), pp. 1578-85.

Rochester, L., Hetherington, V., Jones, D., Nieuwboer, A., Willems, A.M., Kwakkel, G. and Van Wegen, E. (2005) 'The effect of external rhythmic cues (auditory and visual) on walking during a functional task in homes of people with Parkinson's disease', Archives of Physical Medicine and Rehabilitation, 86(5), pp. 999-1006.

Rochester, L., Nieuwboer, A., Baker, K., Hetherington, V., Willems, A.M., Kwakkel, G., Van Wegen, E., Lim, I. and Jones, D. (2008) 'Walking speed during single and dual tasks in Parkinson's disease: Which characteristics are important?', Movement Disorders, 23(16), pp. 2312-2318.

Rochester, L., Yarnall, A.J., Baker, M.R., David, R.V., Lord, S., Galna, B. and Burn, D.J. (2012) 'Cholinergic dysfunction contributes to gait disturbance in early Parkinson's disease', Brain, 135(Pt 9), pp. 2779-88.

Rosano, C., Studenski, S.A., Aizenstein, H.J., Boudreau, R.M., Longstreth, W.T. and Newman, A.B. (2012) 'Slower gait, slower information processing and smaller prefrontal area in older adults', Age Ageing, 41, pp. 58 - 64.

Sheridan, P.L., Solomont, J., Kowall, N. and Hausdorff, J.M. (2003) 'Influence of executive function on locomotor function: divided attention increases gait variability in Alzheimer's disease', Journal of the American Geriatrics Society, 51(11), pp. 1633-7.

Smulders, K., van Nimwegen, M., Munneke, M., Bloem, B.R., Kessels, R.P.C. and Esselink, R.A.J. (2013) 'Involvement of specific executive functions in mobility in Parkinson's disease', Parkinsonism and Related Disorders, 19(1), pp. 126-128.

Stern, Y., Richards, M., Sano, M. and Mayeux, R. (1993) 'Comparison of cognitive changes in patients with alzheimer's and parkinson's disease', Archives of Neurology, 50(10), pp. 1040-1045. 
Stolze, H., Kuhtz-Buschbeck, J.P., Drücke, H., Jöhnk, K., Illert, M. and Deuschl, G. (2001) 'Comparative analysis of the gait disorder of normal pressure hydrocephalus and Parkinson's disease', Journal of Neurology, Neurosurgery \& Psychiatry, 70(3), pp. 289-297.

Studenski, S., Perera, S., Patel, K. and et al. (2011) 'Gait speed and survival in older adults', JAMA, 305(1), pp. 50-58.

Suarez, H., Geisinger, D., Ferreira, E.D., Nogueira, S., Arocena, S., Roman, C.S. and Suarez, A. (2011) 'Balance in Parkinson's disease patients changing the visual input', Brazilian Journal of Otorhinolaryngology, 77, pp. 651-655.

Tabbarah, M., Crimmins, E.M. and Seeman, T.E. (2002) 'The Relationship Between Cognitive and Physical Performance: MacArthur Studies of Successful Aging', The Journals of Gerontology Series A: Biological Sciences and Medical Sciences, 57(4), pp. M228-M235.

Taniguchi, Y., Yoshida, H., Fujiwara, Y., Motohashi, Y. and Shinkai, S. (2012) 'A prospective study of gait performance and subsequent cognitive decline in a general population of older Japanese', Journals of Gerontology Series A-Biological Sciences \& Medical Sciences, 67(7), pp. 796-803.

Tessitore, A., Amboni, M., Cirillo, G., Corbo, D., Picillo, M., Russo, A., Vitale, C., Santangelo, G., Erro, R., Cirillo, M., Esposito, F., Barone, P. and Tedeschi, G. (2012) 'Regional Gray Matter Atrophy in Patients with Parkinson Disease and Freezing of Gait', American Journal of Neuroradiology, 33(9), pp. 1804-1809.

van lersel, M.B., Kessels, R.P., Bloem, B.R., Verbeek, A.L. and Olde Rikkert, M.G. (2008) 'Executive functions are associated with gait and balance in community-living elderly people', Journals of Gerontology Series A-Biological Sciences \& Medical Sciences, 63(12), pp. 1344-9.

Verghese, J., Wang, C., Lipton, R.B., Holtzer, R. and Xue, X. (2007) 'Quantitative gait dysfunction and risk of cognitive decline and dementia', Journal of Neurology, Neurosurgery \& Psychiatry, 78(9), pp. 929-935.

Verlinden, V.J., van der Geest, J.N., Hofman, A. and Ikram, M.A. (2013a) 'Cognition and gait show a distinct pattern of association in the general population', Alzheimers Dement. 
Verlinden, V.J.A., van der Geest, J.N., Hoogendam, Y.Y., Hofman, A., Breteler, M.M.B. and Ikram, M.A. (2013b) 'Gait patterns in a communitydwelling population aged 50 years and older', Gait \& Posture, 37(4), pp. 500505.

Wade, D.T. (1992) 'Measurement in neurological rehabilitation', Curr Opin Neurol Neurosurg, 5(5), pp. 682-6.

Watson, N., Rosano, C., Boudreau, R., Simonsick, E., Ferrucci, L., SuttonTyrrell, K., Hardy, S., Atkinson, H., Yaffe, K., Satterfield, S., Harris, T. and Newman, A. (2010) 'Executive function, memory, and gait speed decline in well-functioning older adults', The Journals of Gerontology: Series A: Biological Sciences and Medical Sciences, 10(10), pp. 1093-1100.

Wild, L.B., de Lima, D.B., Balardin, J.B., Rizzi, L., Giacobbo, B.L., Oliveira, H.B., de Lima, A., II, Peyre-Tartaruga, L.A., Rieder, C.R. and Bromberg, E. (2013) 'Characterization of cognitive and motor performance during dualtasking in healthy older adults and patients with Parkinson's disease', $J$ Neurol, 260(2), pp. 580-9.

Wilkins, A.J., Shallice, T. and McCarthy, R. (1987) 'Frontal lesions and sustained attention', Neuropsychologia, 25(2), pp. 359-365.

Woodruff-Pak, D. and Papka, M. (1999) 'Theories of Neuropsychology in aging', in Bengston, V. and Schaie, K. (eds.) Handbook of the theories of aging. New York: Springer.

Xu, D., Cole, M.H., Mengersen, K., Silburn, P.A., Qiu, F., Graepel, C. and Kerr, G.K. (2014) 'Executive Function and Postural Instability in People with Parkinson's Disease', Parkinson's Disease, 2014, p. 8.

Yarnall, A., Rochester, L. and Burn, D.J. (2011) 'The interplay of cholinergic function, attention, and falls in Parkinson's disease', Mov Disord, 26(14), pp. 2496-503.

Yogev-Seligmann, G., Hausdorff, J.M. and Giladi, N. (2008) 'The role of executive function and attention in gait', Mov Disord, 23(3), pp. 329-42; quiz 472.

Yogev, G., Giladi, N., Peretz, C., Springer, S., Simon, E.S. and Hausdorff, J.M. (2005) 'Dual tasking, gait rhythmicity, and Parkinson's disease: which aspects of gait are attention demanding?', European Journal of Neuroscience, 22(5), pp. 1248-56. 
Yogev, G., Plotnik, M., Peretz, C., Giladi, N. and Hausdorff, J. (2007) 'Gait asymmetry in patients with Parkinson's disease and elderly fallers: when does the bilateral coordination of gait require attention?', Experimental Brain Research, 177(3), pp. 336-346.

Zadikoff, C., Fox, S.H., Tang-Wai, D.F., Thomsen, T., de Bie, R.M.A., Wadia, P., Miyasaki, J., Duff-Canning, S., Lang, A.E. and Marras, C. (2008) 'A comparison of the mini mental state exam to the montreal cognitive assessment in identifying cognitive deficits in Parkinson's disease', Movement Disorders, 23(2), pp. 297-299. 


\section{Figure Captions}

Figure 1: Model of gait proposed by Lord et al, 2013 for older adults. Domains include; Pace, Rhythm, Variability, Asymmetry and postural control.

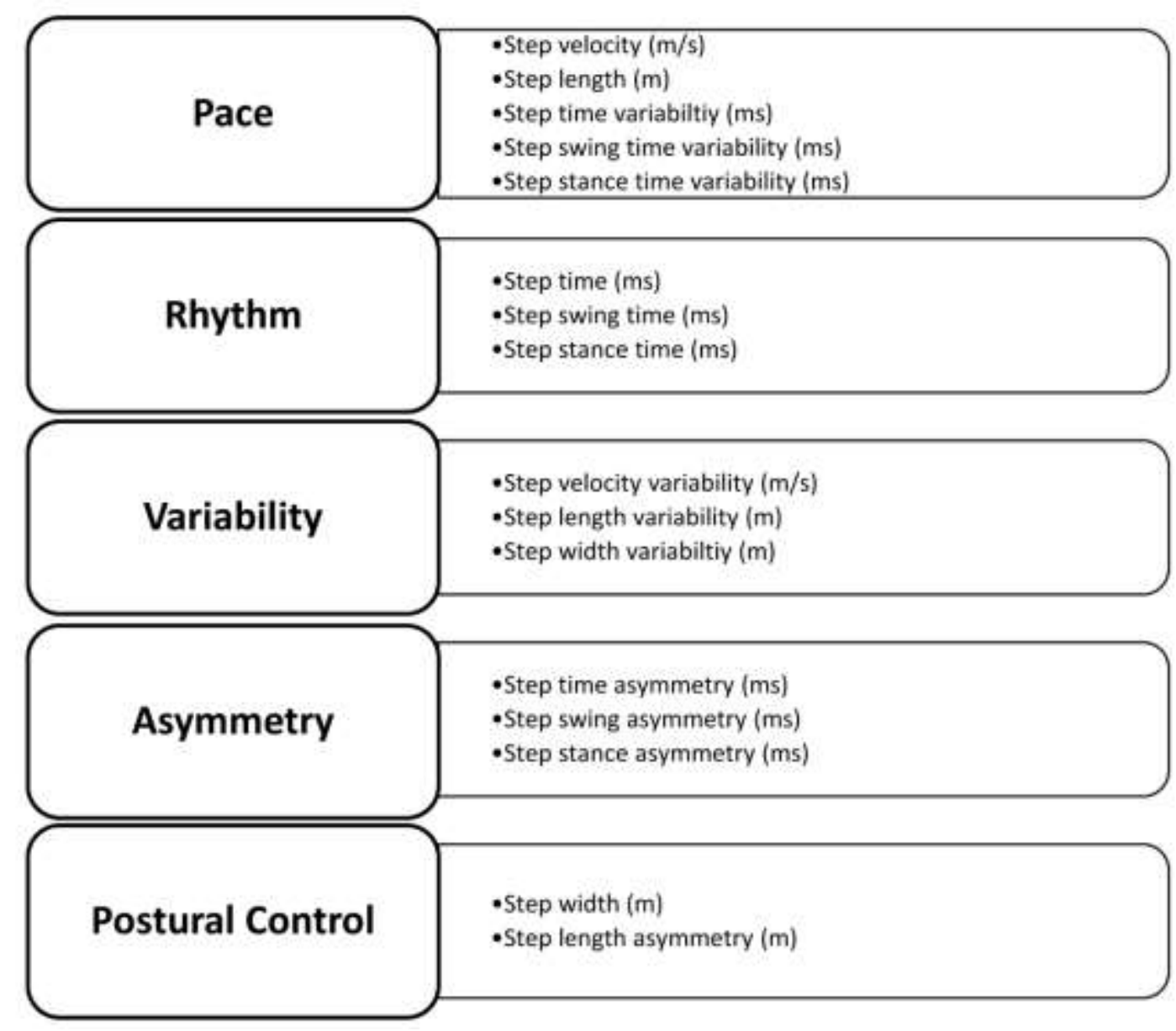


Figure 2: Prisma diagram presenting the search yield for the structured review. Information for exclusion reasons post abstract screen can be found in Results 3.1.

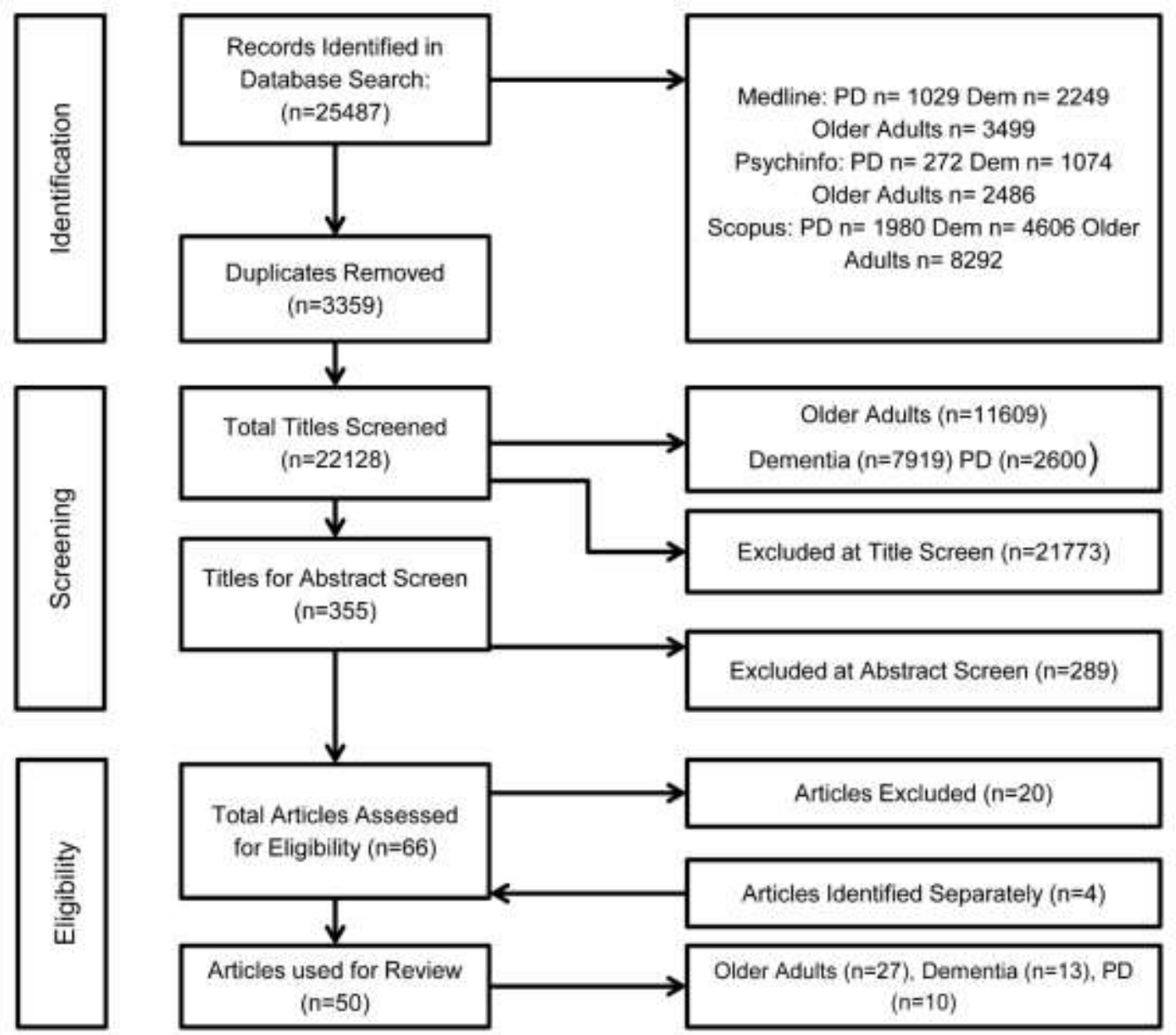


Figure 3: Map of cross sectional associations between gait and cognitive domains in older adults (OA, solid line), cognitive impairment $(\mathrm{Cl}$, dashed line), Parkinson's disease (PD, dotted line).

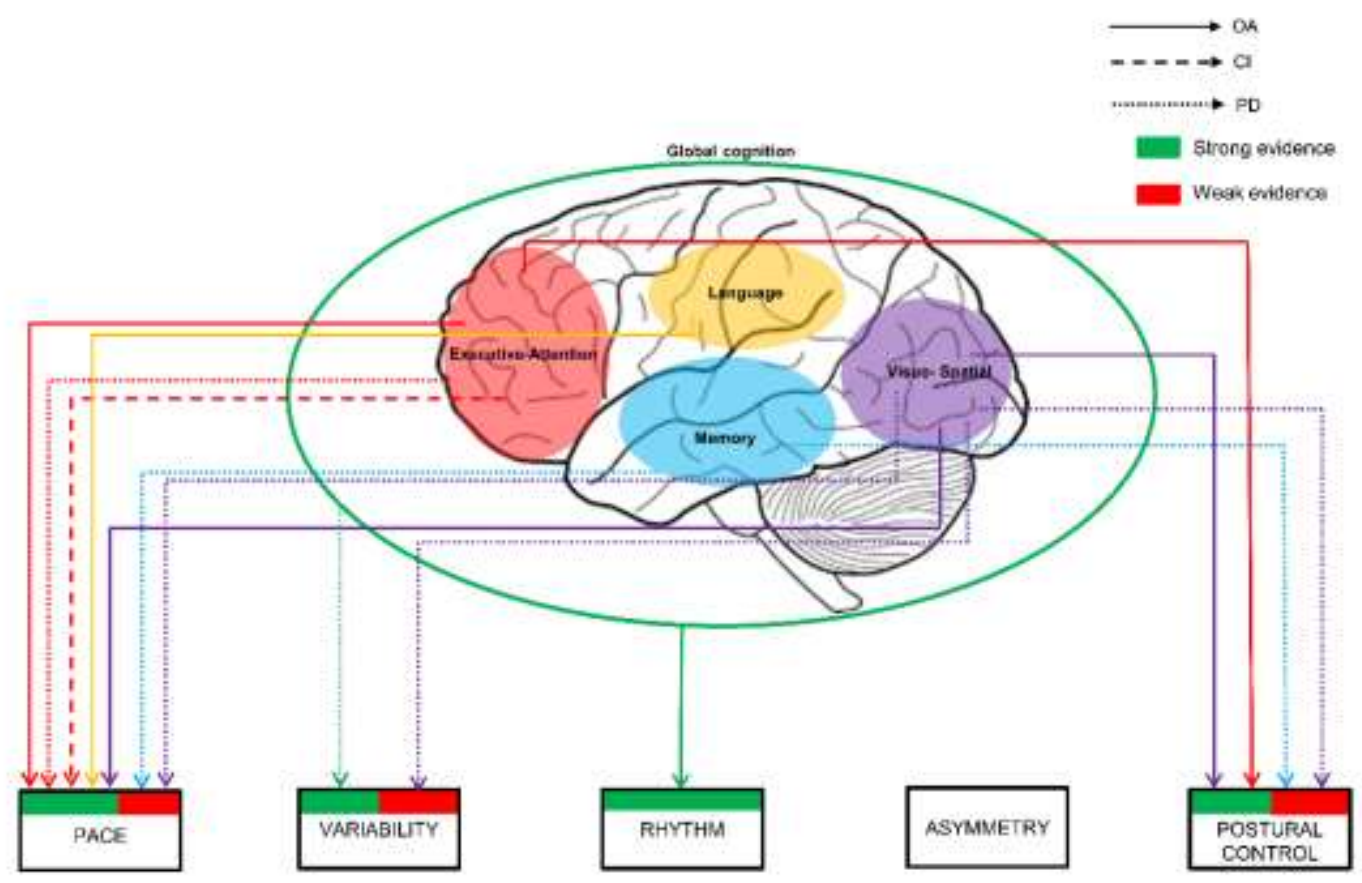


Figure 4: Map of associations between cognitive domains and gait domains longitudinally in older adults.

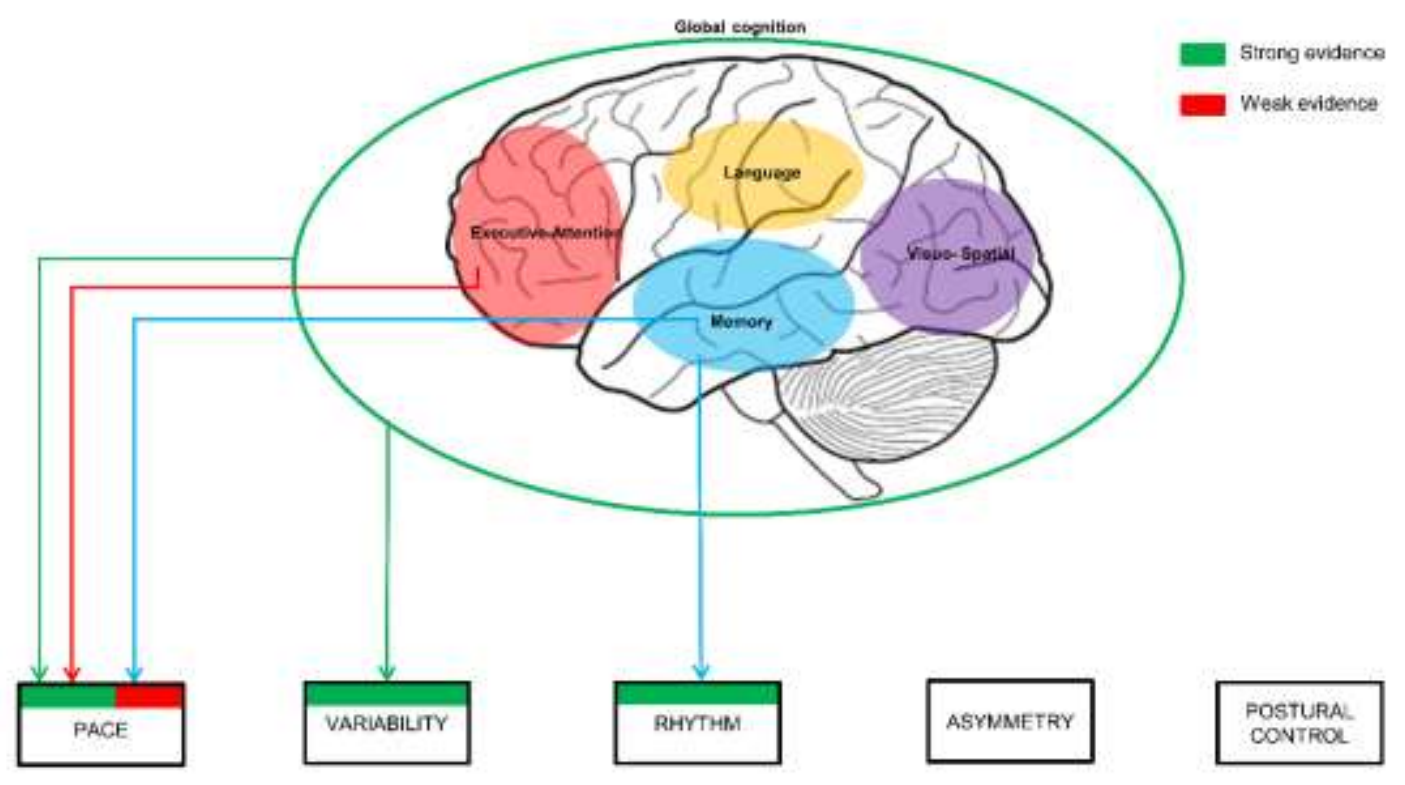


Figure 5: Hypothesised relationship of cognitive decline with respect to the temporal course of decline in gait and cognition in ageing and neurodegenerative disease. (1) Gait and cognition decline concurrently, this may occur in normal ageing - and explains evidence for reverse causality (Tabbarah et al., 2002). (2)The temporal nature of decline with age is unknown, it is unclear therefore if gait and cognition decline together or if one precedes the other in normal ageing (Gale et al., 2014). (3) Neural substrate (pathological change) underpins decline in cognition, but gait proves a more sensitive metric of cognitive change (due to role of cognition in gait) than global cognitive measures which are in common use. (4) Common neural substrate with a different temporal course (pathology affects motor function prior to cognitive function), gait therefore declines prior to cognition.

(2)

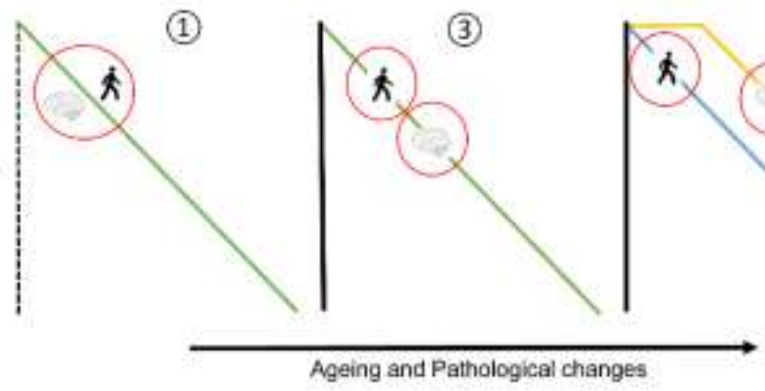

(4)

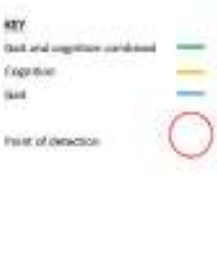

Ageing and Pathological changes

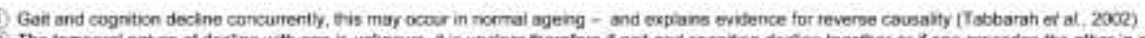

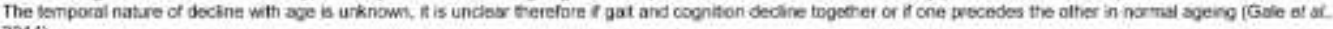

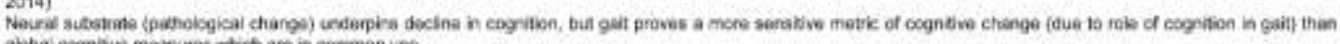

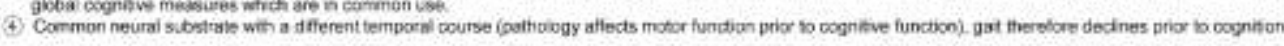


Table 1: Key terms search table used for structured search. Table includes the three databases used, the individual terms for each cohort and MESH headings where applicable.

\begin{tabular}{|c|c|c|c|}
\hline & Medline & Psychinfo & Scopus \\
\hline Gait & $\begin{array}{l}\text { MESH Headings: Gait, locomotion, } \\
\text { walking, } \\
\text { Keywords: symmetry, asymmetry, } \\
\text { frequency, variability, pace, rhythm, } \\
\text { speed, velocity, step }\end{array}$ & $\begin{array}{l}\text { MESH Headings: Gait, locomotion, } \\
\text { walking } \\
\text { Keywords; symmetry, asymmetry, base } \\
\text { of support, frequency, variability, } \\
\text { speed/velocity, stance }\end{array}$ & $\begin{array}{l}\text { Keyword Search: Gait OR locomotion OR } \\
\text { walking OR symmetry OR asymmetry OR } \\
\text { frequency OR variability OR speed OR } \\
\text { velocity OR stance OR step OR swing OR } \\
\text { stride OR "double limb" }\end{array}$ \\
\hline Cognition & $\begin{array}{l}\text { MESH Headings: Cognition, cognition } \\
\text { disorders, memory, neuropsychological } \\
\text { tests, attention, executive function, } \\
\text { reaction time, psychomotor } \\
\text { performance } \\
\text { Keywords; Processing speed, } \\
\text { visuospatial, verbal fluency }\end{array}$ & $\begin{array}{l}\text { MESH Headings; cognition, cognitive } \\
\text { ability (tick spatial ability, verbal ability, } \\
\text { cognitive assessment, cognitive } \\
\text { impairment, cognitive processing } \\
\text { speed, executive function, } \\
\text { metacognition) Memory, Attention, } \\
\text { visuospatial ability, verbal fluency, } \\
\text { reaction time } \\
\text { Keywords; psychomotor performance }\end{array}$ & $\begin{array}{l}\text { Keyword Search: Cognition* OR "global } \\
\text { intelligence" OR cognitive* OR memory OR } \\
\text { attention OR "executive function" OR } \\
\text { "processing speed" OR psychomotor OR } \\
\text { visuospatial OR "verbal fluency" OR } \\
\text { "reaction time" }\end{array}$ \\
\hline \multirow[t]{3}{*}{ Cohort } & $\begin{array}{l}\text { PD: } \\
\text { MESH: Parkinson's disease }\end{array}$ & $\begin{array}{l}\text { PD: } \\
\text { MESH: Parkinson's disease }\end{array}$ & $\begin{array}{l}\text { PD: } \\
\text { Parkinson* }\end{array}$ \\
\hline & $\begin{array}{l}\text { Dementia: } \\
\text { MESH: Dementia (explode), } \\
\text { Alzheimer's disease, }\end{array}$ & $\begin{array}{l}\text { Dementia: } \\
\text { MESH: Dementia (explode dementia- } \\
\text { cognitive impairment, Alzheimer's } \\
\text { disease, dementia with lewy bodies, } \\
\text { vascular dementia) }\end{array}$ & $\begin{array}{l}\text { Dementia: } \\
\text { Alzheimer*, "lewy body", dementia, "frontal } \\
\text { lobe dementia", "intellectual impairment" }\end{array}$ \\
\hline & $\begin{array}{l}\text { Older Adults: } \\
\text { Seniors, older }{ }^{\star} \text {, aging, elderly* }\end{array}$ & $\begin{array}{l}\text { Older Adults: } \\
\text { Seniors, older*, aging, elderly* }\end{array}$ & $\begin{array}{l}\text { Older Adults: } \\
\text { Older* OR elderly* OR Seniors OR aging }\end{array}$ \\
\hline
\end{tabular}


Table 2: Colour correlation table to display gait and cognitive correlations in older adults. Green indicates an association was found, red indicates no association found. 'Beauchet et al. (2012); ${ }^{3} \mathrm{Ble}$ et al. (2005); ${ }^{3}$ Bramell-Risberg et al. (2012); ${ }^{4}$ Donoghue et al. (2012); ${ }^{5}$ Duff et al. (2008); ${ }^{6} \mathrm{Fitzpatrick} \mathrm{et} \mathrm{al.}$ (2007); 7 Hausdorff et al. (2005); ${ }^{8} \mathrm{Hollm}$ man et al. (2007); ${ }^{\circ} \mathrm{Holtzer}$ et al. (2006); ${ }^{10} \mathrm{Holtzer}$ et al. (2012); ${ }^{11} \mathrm{Kaye}$ et al. (2012); ${ }^{12}$ Lord and Menz (2002); ${ }^{13} \mathrm{Lord}$ et al. (2013); ${ }^{14}$ Martin et al. (2013); ${ }^{15}$ van lersel et al. (2008); ${ }^{16}$ Verlinden et al. (2013). From longitudinal studies: ${ }^{17}$ Alfaro-Acha et al. (2007); ${ }^{18} \mathrm{Atkinson}$ et al. (2010); ${ }^{19}$ Deshpande et al. (2009); ${ }^{20}$ Watson et al. (2010). * Referred executive function and attention as 'Executive Attention'. + speed of executive attention

\begin{tabular}{|c|c|c|c|c|c|c|c|}
\hline Domain/Factor & Global cognition & Executive function & Attention & Visuospatial & Memory & Language & \begin{tabular}{|l} 
Processing \\
Speed
\end{tabular} \\
\hline $\begin{array}{l}\text { Pace } \\
\text { Step Velocity }(\mathrm{m} / \mathrm{s}) \\
\text { Step Length }(\mathrm{m}) \\
\text { Step Time Variability (ms) } \\
\text { Step Swing Time Variability } \\
(\mathrm{ms}) \\
\text { Step Stance Time Variability } \\
(\mathrm{ms})\end{array}$ & $\begin{array}{l}4 \bigcirc 5 \bigcirc 17 \bigcirc 19 \\
20 \\
306 \bigcirc 78 \bigcirc 11 \\
12{ }_{13} \bigcirc_{18}\end{array}$ & $\begin{array}{l}1 \bigcirc 4 \bigcirc 7 \bigcirc 9 * 10^{*} \\
14 * 16 \bigcirc 20 \\
2011 \bigcirc 13 \bigcirc 15\end{array}$ & $\begin{array}{l}5 \bigcirc 9 * 11 \bigcirc 13 \\
10 * \bigcirc_{14} * 20\end{array}$ & 5011 & 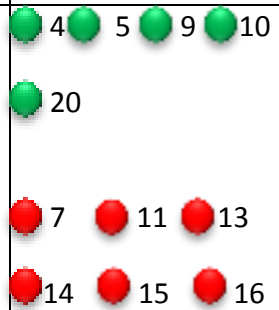 & 509010 & $\begin{array}{l}4 \bigcirc 9+\bigcirc 11 \\
14 \bigcirc 20 \\
16\end{array}$ \\
\hline $\begin{array}{l}\text { Variability } \\
\text { Step Velocity Variability }(\mathrm{m} / \mathrm{s}) \\
\text { Step Length Variability }(\mathrm{m}) \\
\text { Step Width Variability }(\mathrm{m})\end{array}$ & 11013 & $\begin{array}{l}10 * \\
11 \bigcirc 13 \\
16\end{array}$ & $110_{13}$ & 14 & $\begin{array}{lll}10 & 11 & 13 \\
14 & 15 & 16\end{array}$ & 10 & $\begin{array}{ll}11 & 14 \\
16 & \end{array}$ \\
\hline $\begin{array}{l}\text { Rhythm } \\
\text { Step Time (ms) } \\
\text { Step Swing Time (ms) } \\
\text { Step Stance Time (ms) }\end{array}$ & $7 \bigcirc 13$ & $\begin{array}{l}10^{*} \\
7 \bigcirc 13 \bigcirc 14 *{ }_{16}\end{array}$ & $10_{14}^{*}$ & 14 & 10 & & $0^{14} 0^{16}$ \\
\hline $\begin{array}{l}\text { Asymmetry } \\
\text { Step Time Asymmetry (ms) } \\
\text { Step Swing Asymmetry (ms) } \\
\text { Step Stance Asymmetry (ms) }\end{array}$ & 13 & 13 & 13 & & 13 & & \\
\hline $\begin{array}{l}\text { Postural Control } \\
\text { Step Width (m) } \\
\text { Step Length Asymmetry (m) }\end{array}$ & 13 & $\begin{array}{l}13 \bigcirc 14^{*} \\
15 \bigcirc 16\end{array}$ & $14^{*}$ & 014 & $\begin{array}{l}13 \bigcirc \\
16\end{array}$ & & 14 \\
\hline
\end{tabular}


Table 3: Colour correlation table to display cognitive and gait correlations in the cognitive impairment cohort. Green indicates an association was found, red indicates no association found. 'Allali et al. (2010); ${ }^{2}$ Auyeung et al. (2008); ${ }^{3}$ Beauchet et al. (2013); ${ }^{4}$ Coelho et al. (2012); ${ }^{5}$ Gillain et al. (2009); 6ljmker and Lamoth (2012); ${ }^{7}$ Lamoth et al. (2011); ${ }^{8}$ Maquet et al. (2010); 9 McGough et al. (2011), ${ }^{10}$ Muir et al. (2012); 11Persad et al. (2008); 12Sheridan et al. (2003).. ${ }^{*}$ results found for those with dementia as well as healthy controls; analysed as whole cohort. ${ }^{* *} \mathrm{MCl}$ group only. ${ }^{* *} \mathrm{Had} \mathrm{AD}$ or MCI with executive function impairment

\begin{tabular}{|c|c|c|c|c|c|c|c|c|c|c|}
\hline Domain/Factor & $\mathbf{A D}^{+}$ & FTD' & CI & \begin{tabular}{|l|} 
Global \\
Cognition
\end{tabular} & \begin{tabular}{|l|} 
Executive \\
Function \\
\end{tabular} & Attention & Visuospatial & Memory & Language & $\begin{array}{l}\begin{array}{l}\text { Processing } \\
\text { speed }\end{array} \\
\end{array}$ \\
\hline $\begin{array}{l}\text { Pace } \\
\text { Step Velocity }(\mathrm{m} / \mathrm{s}) \\
\text { Step Length }(\mathrm{m}) \\
\text { Step Time Variability }(\mathrm{ms}) \\
\text { Step Swing Time Variability } \\
\text { (ms) } \\
\text { Step Stance Time Variability } \\
(\mathrm{ms})\end{array}$ & $\begin{array}{l}4 \bigcirc 506 \\
8 \bigcirc_{112} \\
1 \bigcirc_{3} \bigcirc_{7}\end{array}$ & $01 \bigcirc 6$ & $0_{3} \mathrm{O}^{\circ}$ & $8^{* *}$ & $\begin{array}{l}911^{* * *} \\
\\
\\
12\end{array}$ & $8^{* *}$ & & & & \\
\hline $\begin{array}{l}\text { Variability } \\
\text { Step Velocity Variability }(\mathrm{m} / \mathrm{s}) \\
\text { Step Length Variability }(\mathrm{m}) \\
\text { Step Width Variability }(\mathrm{m})\end{array}$ & & & & & & & & & & \\
\hline $\begin{array}{l}\text { Rhythm } \\
\text { Step Time (ms) } \\
\text { Step Swing Time (ms) } \\
\text { Step Stance Time (ms) }\end{array}$ & 6 & 06 & $\begin{array}{l}508 \\
10\end{array}$ & $8^{* *}$ & & $8^{* *}$ & & & & \\
\hline $\begin{array}{l}\text { Asymmetry } \\
\text { Step Time Asymmetry (ms) } \\
\text { Step Swing Asymmetry (ms) } \\
\text { Step Stance Asymmetry (ms) }\end{array}$ & & & & & & & & & & \\
\hline $\begin{array}{l}\text { Postural Control } \\
\text { Step Width }(m) \\
\text { Step Length Asymmetry (m) }\end{array}$ & 5 & & $5 \longdiv { 8 }$ & $8^{* *}$ & & $8^{* *}$ & & & & \\
\hline
\end{tabular}


Table 4. Colour correlation table to display cognitive and gait correlations in Parkinson's disease. Green indicates an association was found, red indicates no association found. ${ }^{1}$ Amboni et al. (2012); ${ }^{2}$ Lord et al. (2010); ${ }^{3}$ Lord et al. (2014); ${ }^{4}$ Rochester et al. (2004); ${ }^{5}$ Rochester et al. (2005); ${ }^{6}$ Rochester et al. (2008);

\begin{tabular}{|c|c|c|c|c|c|c|c|}
\hline Domain/Factor & Global Cognition & Executive Function & Attention & Visuospatial & Memory & Language & $\begin{array}{l}\text { Processing } \\
\text { speed }\end{array}$ \\
\hline $\begin{array}{l}\text { Pace } \\
\text { Step velocity ( } \mathrm{m} / \mathrm{s}) \\
\text { Step Length }(\mathrm{m}) \\
\text { Step Time Variability (ms) } \\
\text { Step Swing Time Variability } \\
\text { (ms) } \\
\text { Step Stance Time Variability } \\
\text { (ms) }\end{array}$ & $304 \bigcirc 9$ & $\begin{array}{l}4 \bigcirc 5 \bigcirc 7 \bigcirc 9 \bigcirc 10 \\
1 \bigcirc 2 \bigcirc 68^{* *}\end{array}$ & $\begin{array}{l}203 \\
8^{* *}\end{array}$ & 1 & $\begin{array}{l}3 \\
1\end{array}$ & & \\
\hline $\begin{array}{l}\text { Variability } \\
\text { Step Velocity Variability }(\mathrm{m} / \mathrm{s}) \\
\text { Step Length Variability }(\mathrm{m}) \\
\text { Step Width Variability }(\mathrm{m})\end{array}$ & 3 & 1 & 3 & 1 & $10^{3}$ & & \\
\hline $\begin{array}{l}\text { Rhythm } \\
\text { Step Time (ms) } \\
\text { Step Swing Time (ms) } \\
\text { Step Stance Time (ms) }\end{array}$ & 3 & $\begin{array}{l}3^{*} \\
1048^{* *}\end{array}$ & $38^{* *}$ & 103 & 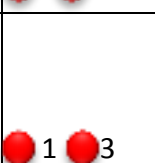 & & \\
\hline $\begin{array}{l}\text { Asymmetry } \\
\text { Step Time Asymmetry (ms) } \\
\text { Step Swing Asymmetry (ms) } \\
\text { Step Stance Asymmetry (ms) }\end{array}$ & 3 & 3 & 3 & 3 & $\mathrm{O}_{3}$ & & \\
\hline
\end{tabular}

Function and attention classified as one domain. 
Table 5. Colour correlation table to display cognitive and gait correlations from longitudinal studies. Green indicates an association was found, red indicates no association found. 'Buracchio et al. (2010); ${ }^{2}$ Dodge et al. (2012); ${ }^{3} \mathrm{Alfaro}-\mathrm{Ach}$ et al. (2007); ${ }^{4}$ Atkinson et al. (2007); ${ }^{5} \mathrm{Atkinson}$ et al. (2010); ${ }^{6} \mathrm{Auyeung}$ et al. (2011); ${ }^{7}$ Deshpande et al. (2009); ${ }^{8}$ Inzitari et al. (2007); ${ }^{9}$ Marquis et al. (2002); ${ }^{10}$ Taniguchi et al. (2012); ${ }^{11}$ Verghese et al. (2007); ${ }^{12}$ Watson et al. (2010). No circle outline $=$ gait as predictor, black circle outline $=$ cognition as a predictor. ${ }^{*}=$ seen at baseline but not longitudinal. ${ }^{* *}=$ associated with the onset of dementia. $t=$ classified as na-MCl where there was an impairment in any domain other than memory but particular domain not specified. + gait speed enhanced prediction model.

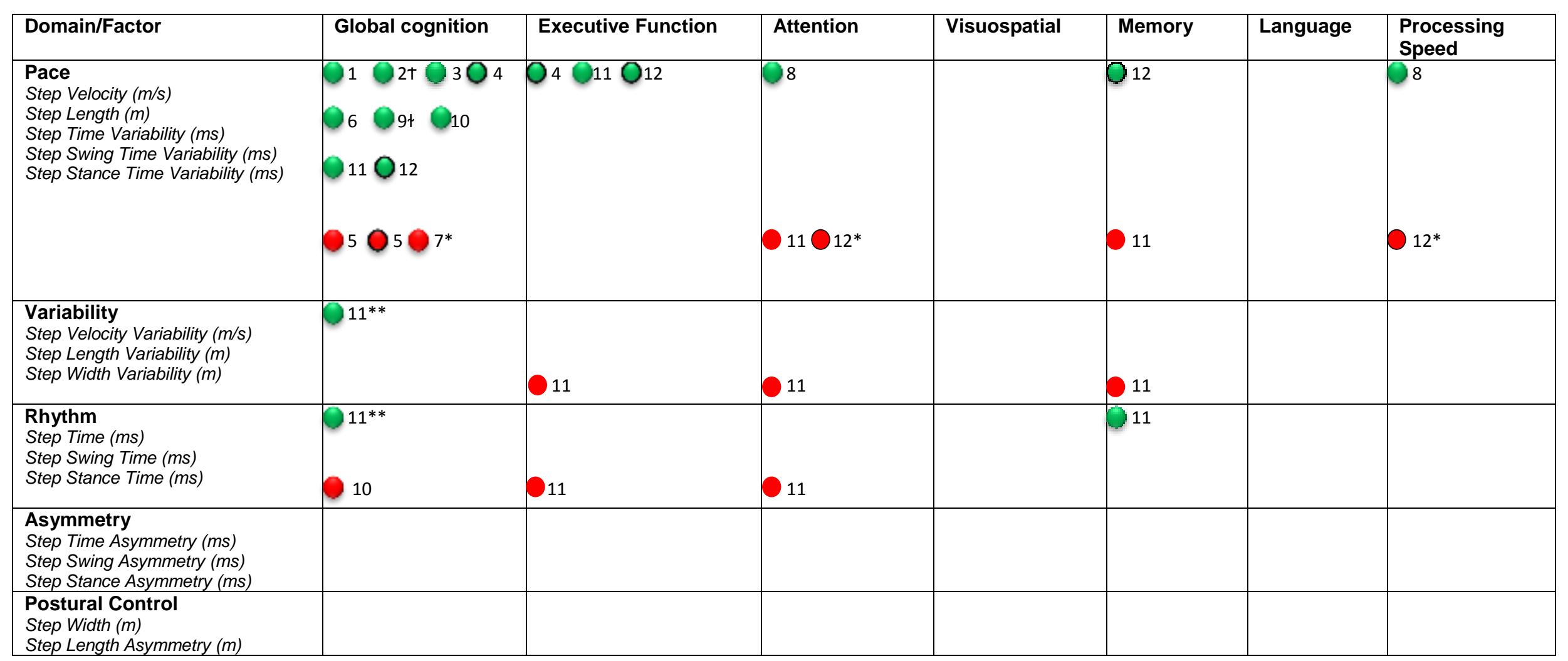


Table 6. Main characteristics of the studies assessing cross-sectional gait and cognitive domains in older adults. Abbreviations as follows; 3MSE, modified mini mental state examination; CDR, cognitive drug research battery; CRT, choice reaction time; CTT, colour trails test; DV, digit vigilance; FCSRT, free and cued selective reminding test; LDST, letter digit substitution test; MMSE, mini mental examination; MoCA, Montreal cognitive assessment; PAL, paired associate learning; PRM, pattern recognition memory; SART, sustained attention response task; SRM, spatial recognition memory; SRT, simple reaction time; TMT, trail making test; TUG, timed up and go; WAIS, Wechsler adult intelligence scale.

\begin{tabular}{|c|c|c|c|c|c|}
\hline Study & Participant Characteristics & Gait Variables Measured & $\begin{array}{l}\text { Gait Analysis } \\
\text { Tool }\end{array}$ & Cognitive Domains Associated & Main Findings \\
\hline $\begin{array}{l}\text { 1. Beauchet et al. } \\
\text { (2012) }\end{array}$ & Older Adults $(n=78)$ Age; $69.9 \pm 0.9$ & Stride Time Variability (\%CV) & $\begin{array}{c}\text { SMTEC Gait } \\
\text { Walkway }(10 m+2 m \\
\text { pre and post) }\end{array}$ & $\begin{array}{l}\text { Executive Function (Digit Span Test, } \\
\text { TMT A \& B, Stroop Colour Word Test) }\end{array}$ & $\begin{array}{l}\uparrow \text { Stride time variability correlated } \\
\text { with } \downarrow \text { executive function. }\end{array}$ \\
\hline 2. Ble et al. (2005) & $\begin{array}{c}\text { Older Adults }(\mathrm{n}=926) \text { Age; } 74.6 \pm 6.7 \\
44 \% \mathrm{M}, \mathrm{MMSE} 25.5 \pm 2.8 \text {, Education } \\
5.6 \pm 3.3\end{array}$ & Gait Velocity (m/sec) & Photocells (4m) & Executive Function (TMT A \& B) & $\begin{array}{l}\text { No correlation found after } \\
\text { adjusting for variables. }\end{array}$ \\
\hline $\begin{array}{l}\text { 3.Bramell-Risberg et } \\
\text { al. (2012) }\end{array}$ & $\begin{array}{l}\text { Older Adults }(\mathrm{n}=2115) \text { split into } 3 \\
\text { groups depending on word recall } \\
\text { score: Cases }(0 / 3) \text {; Age } 75.8 \pm 10.2 \\
\text { Intermediate }(1 / 3) \text { Age } 71.8 \pm 9.5 \\
\text { Controls }(2-3 / 3) \text { Age } 69.0 \pm 9.1\end{array}$ & Gait Velocity $(\mathrm{m} / \mathrm{sec})$ & $\begin{array}{l}\text { TUG }(3 \mathrm{~m} \text {, turn, } 3 \mathrm{~m}) \\
\text { Time to Walk Test } \\
(15 \mathrm{~m}, \text { turn, } 15 \mathrm{~m})\end{array}$ & $\begin{array}{l}\text { Global Cognition (MMSE- } 3 \text { word } \\
\text { delayed recall subsection) }\end{array}$ & $\begin{array}{l}\text { No correlation found at usual } \\
\text { pace walking. }\end{array}$ \\
\hline $\begin{array}{l}\text { 4.Donoghue et al. } \\
\text { (2012) }\end{array}$ & $\begin{array}{c}\text { Older Adults }(\mathrm{n}=4998) \text { Age: } 62 \\
54 \% F, \text { MMSE } 29\end{array}$ & Gait Velocity $(s)$ & TUG (3m, turn, 3m) & $\begin{array}{c}\text { Global Cognition (MMSE, MOCA), } \\
\text { Executive Function (CTT, Clock drawing, } \\
\text { Cube drawing, SART, Word fluency, } \\
\text { Letter fluency), Processing Speed (CTT, } \\
\text { CRT, SART) }\end{array}$ & $\begin{array}{l}\downarrow \text { TUG correlated with } \downarrow \text { global } \\
\text { cognition, EF, memory and } \\
\text { processing speed. }\end{array}$ \\
\hline 5.Duff et al. (2008) & $\begin{array}{l}\text { Older Adults }(\mathrm{n}=675) \text { Age; } 73.2 \pm 5.8 \\
288 \mathrm{M} \& 387 \mathrm{~F}\end{array}$ & $\begin{array}{c}\text { Gait Velocity (s, split into } 3 \\
\text { groups: < } 14 \text { secs, } 14-17 s, \\
\quad>17 s)\end{array}$ & $\begin{array}{l}\text { Time to Walk Test } \\
\text { (25ft, turn, 25ft) }\end{array}$ & $\begin{array}{c}\text { Attention, Language, Visuospatial and } \\
\text { Memory (Repeatable Battery for the } \\
\text { Assessment of Neuropsychological } \\
\text { Status Domains) }\end{array}$ & $\begin{array}{l}\downarrow \text { Velocity was associated with } \downarrow \\
\text { global RBANS score as well as } \\
\text { each RBANS domain. }\end{array}$ \\
\hline $\begin{array}{l}\text { 6.Fitzpatrick et al. } \\
(2007)\end{array}$ & $\begin{array}{l}\text { Older Adults }(\mathrm{n}=3070) \text { Age; } \\
\quad 78.6 \pm 3.3,53.9 \% \mathrm{M}\end{array}$ & Gait Velocity $(\mathrm{m} / \mathrm{s})$ & $\begin{array}{l}\text { Time to Walk Test } \\
\text { (15ft) }\end{array}$ & Global Cognition (3MSE) & $\begin{array}{c}\text { No correlation was found } \\
\text { between gait velocity and global } \\
\text { cognition. } \\
\end{array}$ \\
\hline $\begin{array}{l}\text { 7.Hausdorff et al. } \\
\text { (2005) }\end{array}$ & $\begin{array}{l}\text { Older Adults }(\mathrm{n}=43) \text { Age; } 71.9 \pm 6.4 \\
22 \mathrm{~W} \& 21 \mathrm{M}, \mathrm{MMSE} 29.0 \pm 1.1 \\
\text { Education } 13.7 \pm 2.1\end{array}$ & $\begin{array}{l}\text { Gait Velocity }(\mathrm{m} / \mathrm{s}) \text {, Stride } \\
\text { Time }(\mathrm{s}) \text {, Stride time } \\
\text { Variability (\%CV) }\end{array}$ & $\begin{array}{l}\text { Force-sensitive } \\
\text { Sensors, Time to } \\
\text { Walk }(10 \mathrm{~m}+7.5 \mathrm{~m} \\
\text { pre/post })\end{array}$ & $\begin{array}{c}\text { Global Cognition (MMSE), Executive } \\
\text { Function (Stroop Test), Verbal Memory } \\
\text { (Verbal Memory Test) }\end{array}$ & $\begin{array}{l}\uparrow \text { Stride time variability but not } \\
\text { stride time correlated with } \downarrow \\
\text { executive function after adjusting } \\
\text { for covariates. }\end{array}$ \\
\hline $\begin{array}{l}\text { 8.Hollman et al. } \\
(2007)\end{array}$ & $\begin{array}{r}\text { Older Adults }(\mathrm{n}=20), \text { Age } 81 \pm 5,7 \mathrm{M} \\
\& 13 \mathrm{~W} \\
\text { Middle Aged adults }(\mathrm{n}=20) \text { age } \\
48 \pm 5,9 M \& 11 \mathrm{~W} \\
\text { Younger Adults }(\mathrm{n}=20) \text { age } 25 \pm 3\end{array}$ & $\begin{array}{l}\text { Gait Velocity }(\mathrm{cm} / \mathrm{s}) \text {, Stride } \\
\text { Time Variability }(\% \mathrm{CV})\end{array}$ & $\begin{array}{l}\text { GaitRite } 80 \mathrm{~Hz}(8.3 \mathrm{~m} \\
+1 \mathrm{~m} \text { pre/post } \\
\text { walkway) }\end{array}$ & $\begin{array}{c}\text { Global cognition (Short Test of Mental } \\
\text { Status) }\end{array}$ & $\begin{array}{l}\text { No correlation found under ST } \\
\text { conditions }\end{array}$ \\
\hline
\end{tabular}




\begin{tabular}{|c|c|c|c|c|c|}
\hline & $9 M \& 11 W$ & & & & \\
\hline $\begin{array}{l}\text { 9. Holtzer et al. } \\
(2006)\end{array}$ & $\begin{array}{c}\text { Older Adults }(n=186) \text { Age; } \\
78.00 \pm 4.50,43.4 \% M \text {, Education } \\
14.30 \pm 3.30\end{array}$ & $\begin{array}{c}\text { Gait Velocity }(\mathrm{cm} / \mathrm{s}) \text {, Step } \\
\text { Length }(\mathrm{cm}), \text { Stride Length } \\
(\mathrm{cm}), \text { Stride Length Variability } \\
(\% \mathrm{CV}) \text {, Double Support time } \\
(\mathrm{s})\end{array}$ & $\begin{array}{l}\text { GaitRite (12ft), } \\
\text { including } 3 \mathrm{ft} \text { pre/post } \\
\text { walkway) }\end{array}$ & $\begin{array}{c}\text { Factor analysis domains: Verbal IQ } \\
\text { (Information, vocabulary, digit span, } \\
\text { Boston naming test, FAS). } \\
\text { Attention/Executive speed (Block design, } \\
\text { Digit Symbol, TMT A \& B). Memory } \\
\text { (Category Fluency, FCSRT) }\end{array}$ & $\begin{array}{l}\text { Only correlated gait velocity. All } \\
\text { cognitive domains were } \\
\text { associated. }\end{array}$ \\
\hline $\begin{array}{l}\text { 10.Holtzer et al. } \\
\text { (2012) }\end{array}$ & $\begin{array}{l}\text { Older Adults (N=671) Age; } 79 \pm 5.2 \text {, } \\
60 \% \mathrm{~F} \text {, Education } 13.8 \pm 3.5\end{array}$ & $\begin{array}{c}\text { Gait Velocity }(\mathrm{cm} / \mathrm{s}) \text {, Stride } \\
\text { Length }(\mathrm{cm}), \text { Stride length } \\
\text { Variability }(\% \mathrm{CV}) \text {, Cadence } \\
\text { (Steps/min) }\end{array}$ & $\begin{array}{l}\text { GaitRite }(12 \mathrm{ft} \\
\text { including } 3 \mathrm{ft} \text { pre/post } \\
\text { walkway) }\end{array}$ & $\begin{array}{l}\text { Executive Attention, Memory, Verbal IQ } \\
\text { (Battery Included: Vocabulary, } \\
\text { Information, Digit Span, Digit Symbol, } \\
\text { Block Design, WAIS, FCSRT, total free } \\
\text { recall, Boston Naming Test, letter } \\
\text { fluency, category fluency, TMT A and B) }\end{array}$ & $\begin{array}{l}\text { All domains associated with } \\
\text { pace. Memory and executive } \\
\text { attention correlated with } \\
\text { cadence. } \\
\text { Executive attention was } \\
\text { correlated with stride length } \\
\text { variability. }\end{array}$ \\
\hline 11.Kaye et al. (2012) & $\begin{array}{c}\text { Older Adults }(\mathrm{n}=76) \text { Age; } 85.9 \pm 4.9 \\
86 \% \mathrm{~F}, \mathrm{MMSE} 28.3 \pm 1.7 \text {, Education } \\
15.5 \pm 2.5\end{array}$ & $\begin{array}{l}\text { Gait Velocity }(\mathrm{cm} / \mathrm{s}) \text {, Gait } \\
\text { Velocity }(\% \mathrm{CV}) \text {, Mean } \\
\text { Number walks/day, Number } \\
\text { walks/ day (\%CV) }\end{array}$ & $\begin{array}{l}\text { Passive Infra-red } \\
\text { motion sensor fixed } \\
\text { in-home (Avg } 500 \\
\text { walks per month) }\end{array}$ & $\begin{array}{c}\text { Global Cognition (MMSE), Executive } \\
\text { Function (TMT-B, Category Fluency), } \\
\text { Working Memory (Letter-number } \\
\text { sequencing), Attention/Processing Speed } \\
\text { (Digit Span Forward, Digit Symbol, TMT- } \\
\text { A), Memory (Logical Memory II, Visual } \\
\text { Reproduction II, Word-List Recall), } \\
\text { Visuospatial (Picture Completion, Block } \\
\text { Design) }\end{array}$ & $\begin{array}{l}\uparrow \text { Attention, processing speed and } \\
\text { visuospatial scores associated } \\
\text { with mean } \uparrow \text { walking velocity. }\end{array}$ \\
\hline $\begin{array}{l}\text { 12.Lord and Menz } \\
\text { (2002) }\end{array}$ & $\begin{array}{c}\text { Older Adults }(n=515) \text { Age; } 79.5 \pm 6.4 \\
76 \mathrm{M} \& 439 \mathrm{~F}\end{array}$ & Gait Distance $(m)$ & 6 Minute Walk Test & Global Cognition (MMSE) & $\begin{array}{c}\text { No correlation was found } \\
\text { between gait velocity and global } \\
\text { cognition. }\end{array}$ \\
\hline 13.Lord et al. (2013) & $\begin{array}{l}\text { Older Adults }(n=189) \text { Age; } 69.5 \pm 7.6 \\
\quad 79 M \text { \& } 110 F, M M S E 29.3 \pm 1.0\end{array}$ & $\begin{array}{c}16 \text { Gait Variables into } 5 \\
\text { domains: Pace (step velocity } \\
\text { m/s), mean step length m, } \\
\text { swing time variability ms), } \\
\text { Rhythm (step time ms, swing } \\
\text { time ms, stance time ms), } \\
\text { Variability (step velocity } \\
\text { variability m.s-1, step length } \\
\text { variability m, step time } \\
\text { variability ms, stance time } \\
\text { variability ms), Asymmetry } \\
\text { (swing time asymmetry ms, } \\
\text { step time asymmetry ms, } \\
\text { stance time asymmetry ms), } \\
\text { Postural Control (step length } \\
\text { asymmetry m, step width m, } \\
\text { step width variability m) }\end{array}$ & $\begin{array}{l}\text { GaitRite }(7 \mathrm{~m}), 2 \mathrm{~min} \\
\text { walk around } 25 \mathrm{~m} \\
\text { circuit }\end{array}$ & $\begin{array}{c}\text { Global Cognition (MMSE), Power of } \\
\text { Attention (CDR; SRT, CRT, DV), Memory } \\
\text { (PRM, SRM), Executive Function (One } \\
\text { Touch Stocking of Cambridge) }\end{array}$ & $\begin{array}{l}\uparrow \text { Executive function correlated } \\
\uparrow \text { postural control. } \uparrow A \text { Attention } \\
\text { correlated with } \uparrow \text { pace. }\end{array}$ \\
\hline $\begin{array}{l}\text { 14.Martin et al. } \\
\text { (2013) }\end{array}$ & $\begin{array}{l}\text { Older Adults }(n=422) \text { Age; } 72.0 \pm 7.0 \\
238 M \text { \& } 184 F, \text { GDS } 2.05 \pm 2.3\end{array}$ & $\begin{array}{c}\text { Gait Velocity }(\mathrm{cm} / \mathrm{s}) \text {, Step } \\
\text { Time (ms CV\%), Step Length } \\
\text { (cm, CV\%), Support Base } \\
\text { (cm, CV\%), Double Support } \\
\text { Phase (ms, CV\%) }\end{array}$ & $\begin{array}{l}\text { GaitRite }(4.6 \mathrm{~m},+2 \mathrm{~m} \\
\text { pre/post walkway) }\end{array}$ & $\begin{array}{c}\text { Executive/Attention (Controlled word } \\
\text { association test, category fluency, stoop } \\
\text { test, digit span), Processing Speed } \\
\text { (Symbol Search, Digit Symbol Coding), } \\
\text { Visuospatial Ability (Rey Complex Figure }\end{array}$ & $\begin{array}{c}\text { Executive /Attention correlated } \\
\text { with velocity, step length, step } \\
\text { time variability, double support } \\
\text { time, double support time } \\
\text { variability. }\end{array}$ \\
\hline
\end{tabular}




\begin{tabular}{|c|c|c|c|c|c|}
\hline & & & & $\begin{array}{c}\text { Copy Task), Memory (Hopkins Verbal } \\
\text { Learning Test) }\end{array}$ & $\begin{array}{l}\text { Processing speed correlated with } \\
\text { velocity, step time, step length, } \\
\text { DSP and DSP variability. } \\
\text { Visuospatial correlated with DSP } \\
\text { variability. } \\
\end{array}$ \\
\hline $\begin{array}{l}\text { 15.van lersel et al. } \\
(2008)\end{array}$ & $\begin{array}{c}\text { Older Adults }(\mathrm{n}=100) \text { Age; } 80.6 \pm 4.0 \\
64 \mathrm{M} \& 36 \mathrm{~F}\end{array}$ & $\begin{array}{c}\text { Gait Velocity }(\mathrm{m} / \mathrm{s}) \text { Stride } \\
\text { Length Variability (\%CV), } \\
\text { Stride Time Variability } \\
(\% C V) \text {, Mediolateral body } \\
\text { sway (degrees) }\end{array}$ & $\begin{array}{c}\text { GaitRite }(5.6 m+2 m \\
\text { pre/post walkway) }\end{array}$ & $\begin{array}{c}\text { Executive Function (TMT A \& B, Stroop } \\
\text { Colour-Word Test), Memory (CANTAB; } \\
\text { PAL, PRM) }\end{array}$ & $\begin{array}{l}\text { No correlation found under single } \\
\text { task conditions }\end{array}$ \\
\hline $\begin{array}{l}\text { 16.Verlinden et al. } \\
\text { (2013) }\end{array}$ & $\begin{array}{c}\text { Older Adults }(n=1232) \text { Age; } 66.3 \\
\pm 11.8,558 \mathrm{M} \& 674 \mathrm{~F}, \mathrm{MMSE} 28.0 \pm \\
1.8\end{array}$ & $\begin{array}{l}\text { Factors; Rhythm (single } \\
\text { support time [s], swing time } \\
\text { [s], step time [s], stride time } \\
\text { [s], cadence [steps/min], } \\
\text { stance time [s]) Variability } \\
\text { (stride length SD [cm], step } \\
\text { length SD [cm], stride } \\
\text { velocity SD [cm/s], stride time } \\
\text { SD [s], step time SD [s], } \\
\text { stance time SD [s], swing } \\
\text { time SD [s], single support } \\
\text { time SD [s], double support } \\
\text { time SD [s], Phases (single } \\
\text { support [\%GC], swing } \\
\text { [\%GC], stance [\%GC], } \\
\text { double support [\%GC], } \\
\text { double support time [\%GC], } \\
\text { Pace (stride length [cm], step } \\
\text { length [cm], velocity [cm/s]), } \\
\text { Tandem (Sum of feet surface } \\
\text { [fraction], sum of step } \\
\text { distance [cm], double step } \\
\text { [n]), Turning (turning step } \\
\text { count [n], turning time [s]), } \\
\text { Base of support (stride width } \\
\text { SD [cm], stride width [cm]). }\end{array}$ & GaitRite $(5.79 \mathrm{~m})$ & $\begin{array}{c}\text { Memory (immediate and delayed recall of } \\
15 \text { word verbal learning test), Executive } \\
\text { Function (stroop interference, word } \\
\text { fluency, LDST), Information Processing } \\
\text { Speed (stroop reading, stroop colour } \\
\text { naming \& LDST), Fine Motor Speed } \\
\text { (Purdue Pegboard Test), Global } \\
\text { Cognition (average of all above test } \\
\text { scores) }\end{array}$ & $\begin{array}{l}\text { After adjusting for covariates } \\
\text { (including independence of } \\
\text { cognitive domains); information } \\
\text { processing speed correlated with } \\
\text { rhythm, executive function } \\
\text { associated with pace. }\end{array}$ \\
\hline
\end{tabular}


Table 7. Main characteristics of the studies assessing cross-sectional gait and cognitive domains in the cognitive impairment and dementia. Abbreviations as follows; AD, Alzheimer's disease; ADAS-cog, Alzheimer's disease assessment scale-cognition; CDR, cognitive drug research battery; FAB, frontal assessment battery; FCRT, free and cued recall test; FTD, fronto-temporal dementia; $\mathrm{HC}$, healthy control; $\mathrm{MCl}$, mild cognitive impairment; Dem, dementia; $\mathrm{MCl}-/+\mathrm{EF}, \mathrm{MCl}$ with or without impairment in executive function; MMSE, mini mental examination; MoCA, Montreal cognitive assessment; TAP, test of attentional performance; TMT, trail making test.

\begin{tabular}{|c|c|c|c|c|c|c|}
\hline & Study & Participant Characteristics & $\begin{array}{c}\text { Gait Variables } \\
\text { Measured (Units) }\end{array}$ & $\begin{array}{l}\text { Gait Analysis Tool } \\
\text { (Distance) }\end{array}$ & $\begin{array}{c}\text { Cognitive Domains Tested } \\
\text { (Test Used) }\end{array}$ & Main Study Findings \\
\hline & $\begin{array}{l}\text { Allali et al. } \\
(2010)\end{array}$ & $\begin{array}{c}\text { HC }(n=22) \text { Age } 71.0 \pm 0.5,8 \mathrm{M} \& 14 \mathrm{~F} \\
\text { AD }(n=19) \text { Age } 79.3 \pm 8.466 \mathrm{M} \& \\
13 \mathrm{~F}, \mathrm{MMSE} 19 \pm 7 \\
\text { FTD }(n=19) \text { Age } 66.8 \pm 9.7 \\
10 \mathrm{M} \& 9 \mathrm{~F}, \mathrm{MMSE} 26+6\end{array}$ & $\begin{array}{l}\text { Stride Time (Mean \& } \\
\text { CV) }\end{array}$ & $\begin{array}{l}\text { SMTEC Footswitch } \\
\text { System }(10 \mathrm{~m})\end{array}$ & $\begin{array}{c}\text { Global cognition (MMSE, Mattis } \\
\text { Dementia Rating Scale), Frontal } \\
\text { Cognition (FCRT) }\end{array}$ & $\begin{array}{l}\text { Stride time variability was } \uparrow \text { in FTD } \\
\text { after adjusting for variables. }\end{array}$ \\
\hline & $\begin{array}{l}\text { Auyeung et } \\
\text { al. (2008) }\end{array}$ & $\begin{array}{c}\text { Cognitively Intact }(n=N R) \\
M=72.18 \pm 0.11 W=71.87 \pm 0.13 \\
\text { Cognitively Impaired }(n=N R) M= \\
76.43 \pm 0.59, W=74.64 \pm 0.26\end{array}$ & Gait Velocity $(\mathrm{m} / \mathrm{s})$ & $\begin{array}{l}\text { Timed to Walk Test } \\
(6 \mathrm{~m})\end{array}$ & $\begin{array}{l}\text { Global cognition }(M M S E) \text {, Dementia } \\
\text { Severity (Community Screening } \\
\text { Instrument for Dementia) }\end{array}$ & $\begin{array}{c}\text { Gait velocity correlated with } \mathrm{Cl} \text { in men } \\
\text { and women. }\end{array}$ \\
\hline & $\begin{array}{l}\text { Beauchet et } \\
\text { al. (2013) }\end{array}$ & $\begin{array}{c}\text { HC }(n=44) \text { Age 74.5 } \pm 6.514 \mathrm{M} \& 28 \mathrm{~F} \\
\text { MMSE } 29.0 \pm 1.1 \\
\mathrm{MCl}(\mathrm{n}=39) \text { Age } 73.6 \pm 6.124 \mathrm{M} \& 15 \mathrm{~F} \\
\text { MMSE } 27.8 \pm 1.4 \\
\text { AD with mild dementia }(\mathrm{n}=21) \text { Age } \\
79.2 \pm 5.612 \mathrm{M} \& 21 \mathrm{~F}, \mathrm{MMSE} \\
25.0 \pm 2.3\end{array}$ & $\begin{array}{l}\text { Gait Velocity }(\mathrm{cm} / \mathrm{s}) \text {, } \\
\text { Stride time Variability } \\
\text { (CV\%) }\end{array}$ & $\begin{array}{l}\text { GaitRite } 60 \mathrm{~Hz}(9.72 \mathrm{~m} \\
+2 \mathrm{~m} \text { pre/post } \\
\text { walkway) }\end{array}$ & $\begin{array}{c}\text { Global cognition }(M M S E) \text {, Frontal } \\
\text { lobe assessment }(F A B), A D \text { Severity } \\
(A D A S-C o g)\end{array}$ & $\begin{array}{l}\text { Under usual pace walking there were } \\
\text { no differences between } \mathrm{MCl} \text { or } \mathrm{AD} \\
\text { after adjusting for variables. }\end{array}$ \\
\hline & $\begin{array}{l}\text { Coelho et al. } \\
\text { (2012) }\end{array}$ & $\begin{array}{c}\text { Mild AD }(\mathrm{n}=12) \text { Age } 75.7 \pm 6.8, \text { MMSE } \\
22.0 \pm 2.2 \text {, Education } 5.5 \pm 3.0 \\
\text { Moderate AD }(n=11) \text { Age } 80.1 \pm 7.5 \\
\text { MMSE 16.2 } 2 \text { 2.2, Education } 3.5 \pm 1.1\end{array}$ & $\begin{array}{l}\text { Stride Length }(\mathrm{m}) \\
\text { Stride Speed }(\mathrm{m} / \mathrm{sec}) \\
\text { Cadence (Strides/sec) }\end{array}$ & GaitRite $60 \mathrm{~Hz}(8 \mathrm{~m})$ & $\begin{array}{c}\text { Executive Function (FAB \& Clock } \\
\text { Drawing Test), Attention (Symbol } \\
\text { Search) }\end{array}$ & $\begin{array}{l}\text { Moderate AD had } \downarrow \text { stride length and } \\
\downarrow \text { stride speed compared to mild AD. } \\
\text { Did not assess EF and attention in } \\
\text { association with ST conditions. }\end{array}$ \\
\hline & $\begin{array}{l}\text { Gillain et al. } \\
(2009)\end{array}$ & $\begin{array}{c}\text { HC }(\mathrm{n}=14) \text { Age } 73.53, \mathrm{MMSE} 28.21 \pm \\
1.58, \text { Education 13.71 } \pm 3.73 \\
\mathbf{M C l}(\mathrm{n}=14) \text { Age } 72.85, \mathrm{MMSE} \\
26.71 \pm 1.68 \text {, Education } 13.64 \pm 3.30 \\
\mathrm{AD}(\mathrm{n}=6) \text { Age } 73.66, \mathrm{MMSE} \\
22.83 \pm 2.14, \text { Education } 9.33 \pm 3.78\end{array}$ & $\begin{array}{c}\text { Gait Velocity }(\mathrm{m} / \mathrm{s}), \\
\text { Stride Frequency }(\mathrm{Hz}), \\
\text { Stride Length }(\mathrm{m}), \\
\text { Stride regularity, Stride } \\
\text { symmetry }\end{array}$ & $\begin{array}{l}\text { Locometrix } 3 \text { Axis } \\
\text { Accelerometer }(30 \mathrm{~m})\end{array}$ & $\begin{array}{c}\text { Global cognition (MMSE \& Mattis), } \\
\text { Episodic Memory (Graber \& Buschke- } \\
\text { version of), } \\
\text { Visuoconstructive/Visuospatial ability } \\
\text { (Rey's Complex Figure Test), } \\
\text { Attention (TAP) }\end{array}$ & $\begin{array}{l}\text { Velocity and stride length were } \downarrow \text { in } \\
\text { AD compared to } \mathrm{HC} \text {. } \\
\text { Those with } \mathrm{MCl} \text { had } \downarrow \text { stride } \\
\text { frequency compared to HC. } \\
\text { Associations between domains under } \\
\text { ST conditions were unclear. }\end{array}$ \\
\hline & $\begin{array}{l}\text { ljmker and } \\
\text { Lamoth } \\
\text { (2012) }\end{array}$ & $\begin{array}{c}\text { HC Elderly }(n=14) \text { Age } 76.9 \pm 4.1 \\
12 M \& 2 F, M M S E 28.5 \pm 1.16 \\
\text { HC Younger }(n=12) \text { Age } 64.3 \pm 2.8 \\
\text { 9M \& } 3 F, M M S E 29.1 \pm 0.93 \\
\text { Dem }(A D \text { and FTD, } n=15) \text { Age } \\
81.7 \pm 6.3,13 M \text { and } 2 F, M M S E \\
19.6 \pm 3.58\end{array}$ & $\begin{array}{c}\text { Gait velocity }(\mathrm{m} / \mathrm{s}), \\
\text { mean stride time }(\mathrm{m}) \text {, } \\
\text { stride time variability } \\
(\% \mathrm{CV})\end{array}$ & $\begin{array}{l}\text { Dynaport@Ambulant } \\
\text { Accelerometer ( } 3 \text { mins } \\
\text { on } 10 \mathrm{~m} \text { course })\end{array}$ & $\begin{array}{c}\text { Global cognition (MMSE), Processing } \\
\text { speed (Category Fluency), } \\
\text { Psychomotor Speed (Stroop), } \\
\text { Executive Function (Stroop), } \\
\text { Attention (Digit Span } \\
\text { Forward/Backward \& TMT), Working } \\
\text { Memory (Digit Span) }\end{array}$ & $\begin{array}{l}\text { Those with Dem had } \downarrow \text { gait velocity; } \uparrow \\
\text { stride time and } \uparrow \text { stride time variability } \\
\text { compared to both HC groups. } \\
\text { Cognitive domains associated with } \\
\text { gait as whole cohort only so therefore } \\
\text { not reported. }\end{array}$ \\
\hline & $\begin{array}{l}\text { Lamoth et al. } \\
\text { (2011) }\end{array}$ & $\begin{array}{c}\text { HC }(n=13) \text { Age } 79.38 \pm 5.55 \\
\text { 10M\&16F, MMSE } 28.23 \pm 1.09 \\
\text { AD }(n=13) \text { Age } 82.62 \pm 4.29,6 M \& 7 F \\
\text { MMSE } 18.00 \pm 3.54\end{array}$ & $\begin{array}{l}\text { Gait Velocity }(\mathrm{m} / \mathrm{sec}), \\
\text { Stride Frequency } \\
\text { (strides/sec), Stride } \\
\text { Time }(\mathrm{s}), \text { Stride Time } \\
\text { Variability }(\% \mathrm{CV}),\end{array}$ & $\begin{array}{c}\text { Timed to walk test, } \\
\text { Dynaportß Tri-Axial } \\
\text { Ambulant } \\
\text { Accelerometer }(160 \mathrm{~m})\end{array}$ & $\begin{array}{c}\text { Global cognition (MMSE, 7min } \\
\text { Screening) }\end{array}$ & $\begin{array}{l}\text { No correlations found under ST } \\
\text { conditions. }\end{array}$ \\
\hline
\end{tabular}




\begin{tabular}{|c|c|c|c|c|c|}
\hline & & $\begin{array}{c}\text { Phase Variability Index } \\
(\%)\end{array}$ & & & \\
\hline $\begin{array}{l}\text { 8. Maquet et al. } \\
(2010)\end{array}$ & $\begin{array}{c}\mathrm{HC}(\mathrm{n}=14) \text { Age } 74 \pm 5,7 \mathrm{M} \& 7 \mathrm{~F} \\
\text { MCl }(\mathrm{n}=14) \text { Age } 73 \pm 4,7 \mathrm{M} \& 7 \mathrm{~F} \\
\text { Mild } \mathbf{A D}(\mathrm{n}=6) \text { Age } 74 \pm 4,3 \mathrm{M} \& 3 \mathrm{~F}\end{array}$ & $\begin{array}{l}\text { Gait Velocity }(m s-1), \\
\text { Stride Frequency }(H z), \\
\text { Stride length }(m), \text { Step } \\
\text { Asymmetry }(\text { Sym })\end{array}$ & $\begin{array}{c}\text { Locometrix }{ }^{\mathrm{TM}} \\
\text { Acceleration Sensor } \\
(90 \mathrm{~m})\end{array}$ & $\begin{array}{c}\text { Global Cognition (MMSE \& Mattis), } \\
\text { Episodic Memory (Grober \& } \\
\text { Buschke), } \\
\text { Visuoconstruction/Visuospatial Ability } \\
\text { (Rey's Complex Figure Test), } \\
\text { Attention (TAP) }\end{array}$ & $\begin{array}{c}\downarrow \text { gait velocity and } \downarrow \text { stride length in } \mathrm{AD} \\
\text { compared to } \mathrm{HC} \text { and } \mathrm{MCl} \text {. MCl s.d to } \\
\text { controls for stride } \\
\text { In MCl group, correlation between } \\
\downarrow \text { velocity and } \downarrow \text { stride length and } \\
\downarrow \text { cognition and } \downarrow \text { attention and stride } \\
\text { frequency and global cognition. }\end{array}$ \\
\hline $\begin{array}{l}\text { 9. McGough et } \\
\text { al. (2011) }\end{array}$ & $\begin{array}{c}\mathbf{C l}(\mathrm{n}=201) \text { Age; } 84.6 \pm 5.7,80.1 \% \\
\text { female, high school educated } 97.5 \%\end{array}$ & Gait Velocity $(\mathrm{m} / \mathrm{s})$ & $\begin{array}{c}\text { Timed to Walk Test } \\
(2.4 \mathrm{~m})\end{array}$ & $\begin{array}{c}\text { Executive Function (TMT-B \& Stroop } \\
\text { Word-Colour) }\end{array}$ & $\begin{array}{l}\downarrow \text { gait velocity associated with lower } \\
\text { executive function score }\end{array}$ \\
\hline $\begin{array}{l}\text { 10. Muir et al. } \\
\text { (2012) }\end{array}$ & 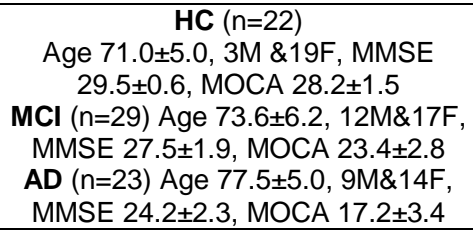 & $\begin{array}{l}\text { Gait Velocity }(\mathrm{cm} / \mathrm{s}) \\
\text { Stride Time }(\mathrm{ms}) \text { Stride } \\
\text { Time Variability }(\mathrm{CV} \%)\end{array}$ & $\begin{array}{l}\text { GaitRite }(6 m+1 m \\
\text { pre/post walkway) }\end{array}$ & $\begin{array}{c}\text { Global Cognition (MMSE, MOCA, } \\
C D R)\end{array}$ & $\begin{array}{l}\text { No difference in gait variables under } \\
\text { ST conditions }\end{array}$ \\
\hline $\begin{array}{l}\text { 11. Persad et al. } \\
(2008)\end{array}$ & 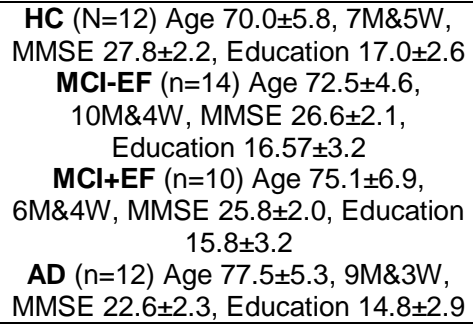 & Gait Velocity $(s)$ & $\begin{array}{c}\text { Timed to Walk Test } \\
(10 \mathrm{~m})\end{array}$ & $\begin{array}{c}\text { Executive Function (Map Planning \& } \\
\text { Paper Folding), Visual Short Term } \\
\text { Attention (Corsi Block Task \& Benton } \\
\text { Form Visual Discrimination), Visuo- } \\
\text { Motor (Block-Design), Memory } \\
\text { (Delayed Recall) }\end{array}$ & $\begin{array}{l}\text { Those with } \mathrm{AD} \text { and } \mathrm{MCl}+\mathrm{EF} \text { had a } \\
\downarrow \text { gait velocity compared to } \mathrm{HC} \text { and } \\
\mathrm{MCl}-\mathrm{EF} \text {. Walking speed correlated } \\
\text { with } \mathrm{EF} \text {. }\end{array}$ \\
\hline $\begin{array}{l}\text { 12. Sheridan et } \\
\text { al. (2003) }\end{array}$ & $\begin{array}{c}\text { Patients diagnosed with probable } \\
\text { AD }(n=28) \text { Age; } 77.9 \pm 6.9, \text { MMSE } \\
13.8 \pm 7.9\end{array}$ & $\begin{array}{c}\text { Velocity (msec), } \\
\text { Stride Time Variability } \\
(\% \mathrm{CV})\end{array}$ & $\begin{array}{c}\text { Footswitch System } \\
(100 \mathrm{~Hz}) \\
(\sim 500 \mathrm{ft})\end{array}$ & $\begin{array}{c}\text { Global Cognition (MMSE), Executive } \\
\text { Function (Clox I \& II, Verbal Fluency) } \\
\text { Dementia Severity (CDR) }\end{array}$ & $\begin{array}{c}\text { Those with AD had } \downarrow \text { gait velocity and } \\
\uparrow \text { increased stride time variability. No } \\
\text { correlation with executive function } \\
\text { under ST conditions }\end{array}$ \\
\hline
\end{tabular}


Table 8. Main characteristics of the studies assessing cross-sectional gait and cognitive domains in Parkinson's disease. Abbreviations as follows; FAB, frontal assessment battery; FOG-Q, freezing of gait questionnaire; H \& Y, Hoehn \& Yahr disease severity classification; $\mathrm{HC}$, healthy controls; MCl; mild cognitive impairment; $\mathrm{MCl}+\mathrm{MCl}$-, with/without mild cognitive impairment; MMSE, mini mental examination; MoCA, Montreal cognitive assessment; PD, Parkinson's disease; UPDRS, unified Parkinson's disease rating scale.

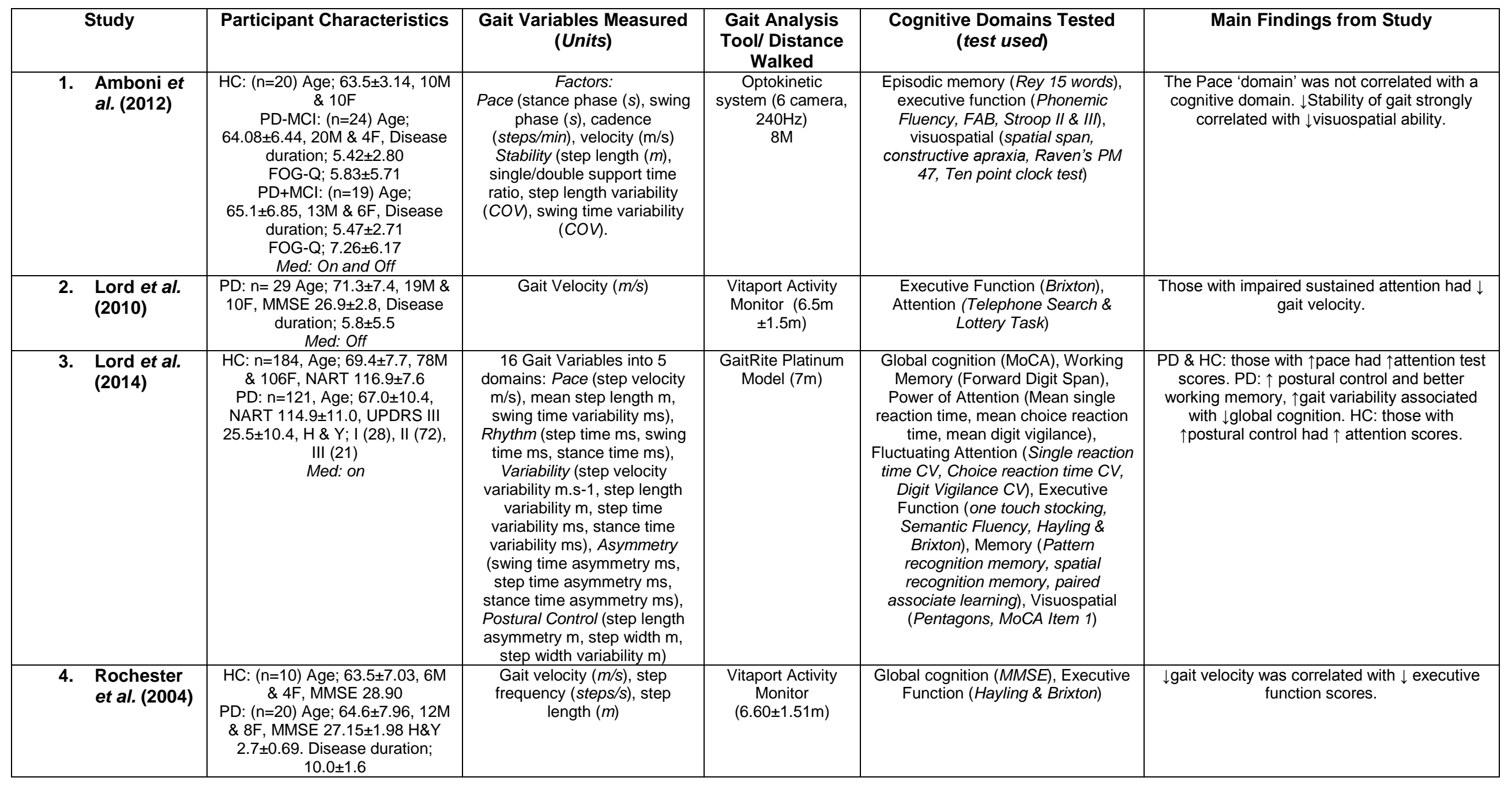




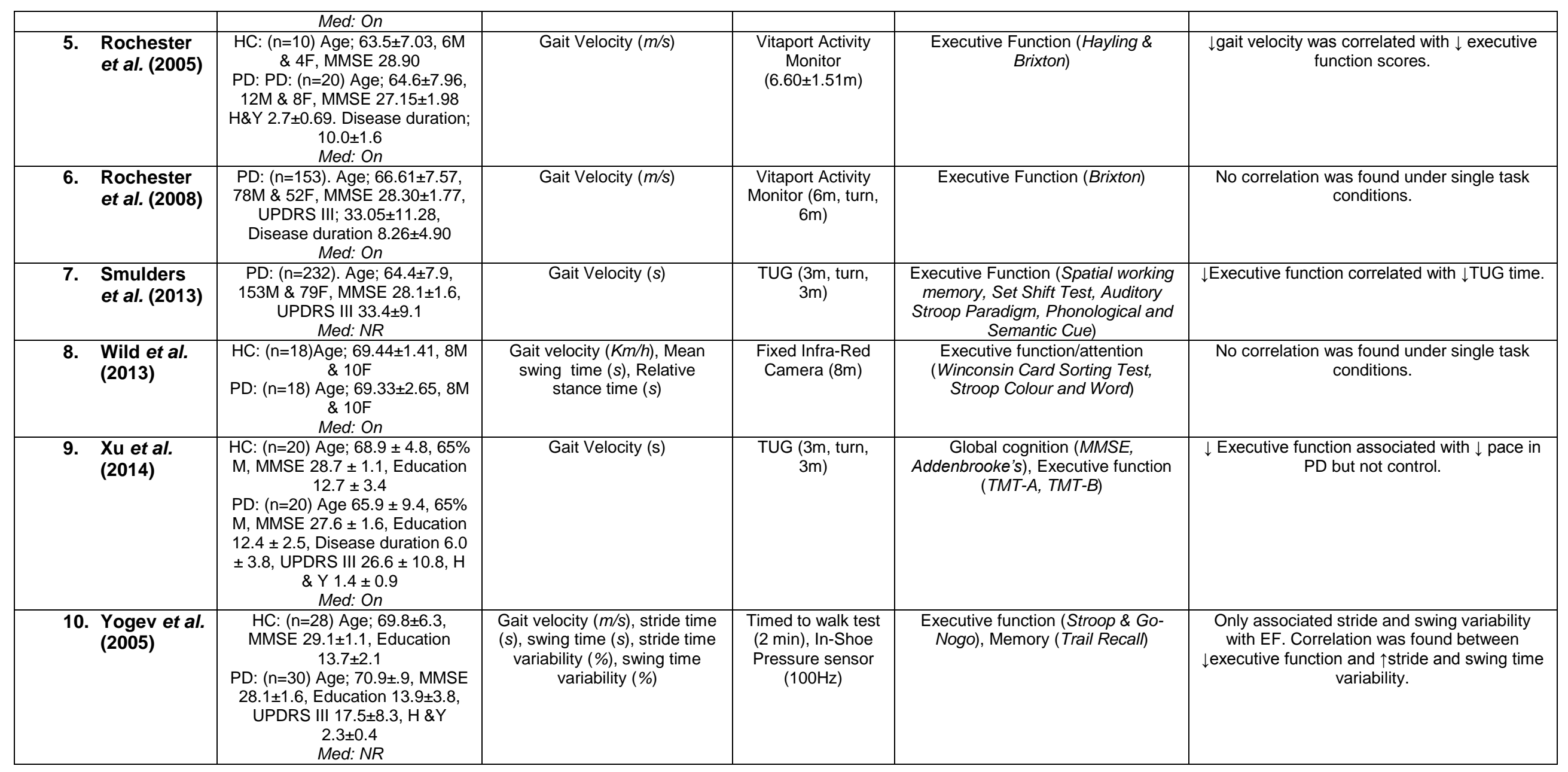


Table 9. Main characteristics of the studies assessing longitudinal gait and cognitive domains in older adults. Abbreviations as follows; 3MS, modified mini mental state examination; a/na MCl, amnestic/ non-amnestic mild cognitive impairment; CDR, cognitive drug research battery; EXIT 15, the executive interview; $\mathrm{MCl}$, mild cognitive impairment; MMSE, mini mental examination; TMT, trail making test; WAIS, Wechsler adult intelligence scale.

\begin{tabular}{|c|c|c|c|c|c|c|}
\hline & Study & Participant Characteristics & $\begin{array}{c}\text { Gait Variables } \\
\text { Measured (Units) }\end{array}$ & $\begin{array}{l}\text { Gait Analysis Tool } \\
\text { (Distance) }\end{array}$ & $\begin{array}{c}\text { Cognitive Domains Tested } \\
\text { (Test used) }\end{array}$ & Main Study Findings \\
\hline & $\begin{array}{l}\text { Buracchio et } \\
\text { al. (2010) }\end{array}$ & $\begin{array}{c}\text { HC }(\mathrm{n}=109) \text { Age } 79.0 \pm 8.8,60 \mathrm{M} \\
\& 49 \mathrm{~F}, \mathrm{MMSE} 28.3 \pm 1.5 \text {, Years } \\
\text { Education } 14.5 \pm 2.7 \\
\text { Converters to } \mathrm{MCl}(\mathrm{n}=95) \text { Age } \\
83.5 \pm 7.0,37 \mathrm{M} \& 58 \mathrm{~F}, \mathrm{MMSE} \\
28.1 \pm 1.6, \text { Education } 14.7 \pm 2.6\end{array}$ & Gait Velocity $(\mathrm{m} / \mathrm{s})$ & $\begin{array}{l}\text { Timed to Walk Test } \\
\text { (30ft) }\end{array}$ & $\begin{array}{c}\text { Global Cognition (MMSE), } \\
\text { Dementia Rating Scale }(C D R)\end{array}$ & $\begin{array}{l}\text { Those who converted to } \mathrm{MCl} \text { had } \downarrow \text { gait } \\
\text { velocity up to } 12.1 \text { years prior to } \mathrm{MCl} \text {. }\end{array}$ \\
\hline 2. & $\begin{array}{l}\text { Dodge et al. } \\
\text { (2012) }\end{array}$ & $\begin{array}{c}\mathrm{HC}(\mathrm{n}=54) \text { Age } 84.9 \pm 4.0,91 \% \\
\text { female, MMSE } 29.0 \pm 1.3 \\
\text { aMCl }(\mathrm{n}=8) \text { Age } 84.5 \pm 2.6,88 \% \\
\text { female, MMSE } 28.3 \pm 1.2 \text { naMCl } \\
(\mathrm{n}=31) \text { Age } 83.8 \pm 6.0,84 \% \\
\text { female, MMSE } 28.1 \pm 1.6\end{array}$ & $\begin{array}{l}\text { Gait velocity }(\mathrm{cm} / \mathrm{s}) \\
\text { Gait velocity } \\
\text { variability }(\% \mathrm{CV})\end{array}$ & $\begin{array}{l}\text { Passive Infra-red } \\
\text { motion sensor fixed in- } \\
\text { home }\end{array}$ & $\begin{array}{c}\text { Global Cognition (MMSE), } \\
\text { Memory (Logical Memory } \\
\text { Delayed), Executive Function } \\
\text { (Category Fluency, TMT Part B), } \\
\text { Attention (WAIS Digit Symbol), } \\
\text { Language (Boston Naming Test), } \\
\text { Visuospatial (WAIS Revised Block } \\
\text { Design) }\end{array}$ & $\begin{array}{l}\text { naMCI had } \downarrow \text { gait velocity compared to } \\
\mathrm{HC} \text { and showed decline in gait velocity } \\
\text { over time, those with naMCI had } \uparrow \text { gait } \\
\text { speed variability in the home. }\end{array}$ \\
\hline 3. & $\begin{array}{l}\text { Alfaro-Acha et } \\
\text { al. (2007) }\end{array}$ & $\begin{array}{c}\text { Older Adults }(\mathrm{n}=1218) \text { Age; } \\
71.7 \pm 5.7,57.5 \% \mathrm{~F}, \mathrm{MMSE} \\
26.5 \pm 2.9, \text { Education } 5.4 \pm 3.9\end{array}$ & $\begin{array}{c}\text { Gait Velocity (Split } \\
\text { into quartiles: } 1 ; \geq 9 s \text {, } \\
2 ; 6-8 s, 3 ; 4-5 s, 4 ; \\
<4 s)\end{array}$ & Time to Walk Test (8ft) & Global Cognition (MMSE) & $\begin{array}{l}\text { No correlation at baseline. At } 7 \text { year } \\
\text { follow up association between slow gait } \\
\text { velocity and } \downarrow \text { cognition. }\end{array}$ \\
\hline 4. & $\begin{array}{l}\text { Atkinson et al. } \\
(2007)\end{array}$ & $\begin{array}{l}\text { Older Adults }(\mathrm{n}=2349) \text { Age; } \\
75.6 \pm 2.9,52.3 \% \mathrm{~F}\end{array}$ & Gait Velocity $(\mathrm{m} / \mathrm{s})$ & $\begin{array}{l}\text { Time to Walk Test } \\
(20 \mathrm{~m})\end{array}$ & $\begin{array}{c}\text { Global Cognition (MMSE, 3MS), } \\
\text { Executive Function (Clox 1, EXIT } \\
15)\end{array}$ & $\begin{array}{c}\text { Greater gait velocity decline over } 3 \text { years } \\
\text { was seen in those with lowest cognition } \\
\text { and EF scores. }\end{array}$ \\
\hline 5. & $\begin{array}{l}\text { Atkinson et al. } \\
(2010)\end{array}$ & $\begin{array}{c}\text { Older Adults }(n=1793) \text { Age; } \\
70.3 \pm 3.7,3 M S \text { Score } 95.1 \pm 4.4\end{array}$ & Gait Velocity $(\mathrm{m} / \mathrm{s})$ & Time to Walk Test $(6 \mathrm{~m})$ & Global Cognition (3MS) & $\begin{array}{l}\text { Gait speed was not associated with 3MS } \\
\text { score at baseline when adjusting for } \\
\text { covariates. Baseline 3MS did not predict } \\
\text { decline in gait speed (or vice versa) after } \\
\text { adjusting for covariates. }\end{array}$ \\
\hline 6. & $\begin{array}{l}\text { Auyeung et al. } \\
\text { (2011) }\end{array}$ & $\begin{array}{c}\text { Older Adults }(n=2737) \mathrm{M}=1514 \\
\text { Age } 71.6 \pm 4.58, \mathrm{MMSE} \\
27.4 \pm 2.25 \\
\mathrm{~F}=1223 \mathrm{Age} 71.5 \pm 4.85 \mathrm{MMSE} \\
25.8 \pm 2.80\end{array}$ & $\begin{array}{l}\text { Gait Velocity }(\mathrm{m} / \mathrm{s}) \\
\text { Step Length }(\mathrm{m}) \\
\text { Step Number }\end{array}$ & Time to Walk Test $(6 \mathrm{~m})$ & Global Cognition (MMSE) & $\begin{array}{l}\text { In male subjects, stride length correlated } \\
\text { with decline MMSE score but not gait } \\
\text { velocity after adjusting for covariates. }\end{array}$ \\
\hline 7. & $\begin{array}{l}\text { Deshpande et } \\
\text { al. (2009) }\end{array}$ & $\begin{array}{c}\text { Older Adults }(\mathrm{n}=660) \text { Age; } \\
74.6 \pm 5.3,54.2 \% \mathrm{~F} \text {, Education } \\
5.8 \pm 3.4\end{array}$ & Gait Velocity $(\mathrm{m} / \mathrm{s})$ & $\begin{array}{l}\text { Timed to Walk Test } \\
(7 \mathrm{~m})\end{array}$ & Global Cognition (MMSE) & $\begin{array}{l}\text { Baseline; those with } \downarrow \text { MMSE had } \downarrow \text { gait } \\
\text { speed. } \\
\text { Longitudinal; Gait velocity at fast pace } \\
\text { only predicted decline in cognition. }\end{array}$ \\
\hline & $\begin{array}{l}\text { Inzitari et al. } \\
(2007)\end{array}$ & $\begin{array}{l}\text { Older Adults }(n=3075) \text { Age; } \\
73.6 \pm 2.9,1491 \mathrm{M} \& 1584 \mathrm{~F}\end{array}$ & Gait Velocity $(\mathrm{m} / \mathrm{s})$ & $\begin{array}{l}\text { Timed to Walk Test } \\
\qquad(6 \mathrm{~m})\end{array}$ & $\begin{array}{l}\text { Global Cognition (3MS), Attention } \\
\text { and Psychomotor Speed (Digit } \\
\text { Symbol Substitution Test) }\end{array}$ & $\begin{array}{l}\uparrow \text { global cognition scores related to } \uparrow \text { gait } \\
\text { speed. Gait speed predicted } \downarrow \text { attention } \\
\text { and } \downarrow \text { psychomotor speed at } 5 \text { years. } \\
\text { Difference in gait speed at baseline } \\
\text { related to } \uparrow \text { risk of decline in attention and }\end{array}$ \\
\hline
\end{tabular}




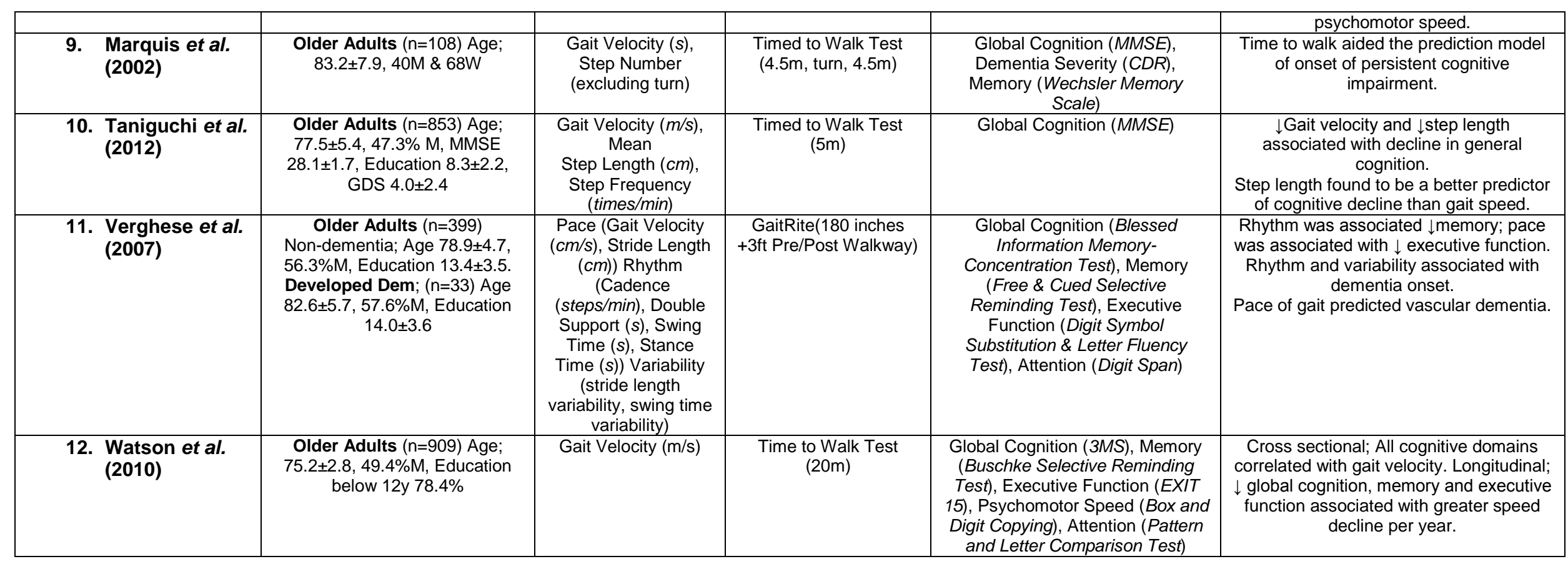

